\title{
Technical assistance and training for PROCOSI operations research program, Bolivia
}

Fernando Gonzales Salguero

Population Council

Ricardo Vernon

Population Council

Follow this and additional works at: https://knowledgecommons.popcouncil.org/departments_sbsr-rh

Part of the Demography, Population, and Ecology Commons, Health Services Research Commons, and the International Public Health Commons

How does access to this work benefit you? Let us know!

\section{Recommended Citation}

Gonzales Salguero, Fernando and Ricardo Vernon. 2005. "Technical assistance and training for PROCOSI operations research program, Bolivia," FRONTIERS Final Report. Washington, DC: Population Council. 


\title{
Final Report
}

\section{Technical Assistance and Training for PROCOSI Operations Research Program, Bolivia}

\author{
Fernando Gonzáles S. \\ Ricardo Vernon
}

January 2005

This study was funded by the U.S. AGENCY FOR INTERNATIONAL DEVELOPMENT (USAID) under the terms of Cooperative Agreement Number HRN-A-00-98-00012-00 and Population Council In-house project number 8000 13036. The opinions expressed herein are those of the author and do not necessarily reflect the views of USAID. 


\section{SUMMARY}

In September 1999, PROCOSI, a network of 24 non-governmental organizations (NGOs) that provide health services, invited the Population Council Frontiers in Reproductive Health Program to provide technical assistance for designing and conducting operations research aimed at increasing the quality and impact of their reproductive health programs. In October 1999, FRONTIERS and PROCOSI held a workshop for designing operations research. Sixteen project proposals were developed at the workshop, and twelve of them were approved for funding during the following months. Also, between March and September 2000, four new projects were developed and approved, making a total of 16 operations research projects. They were originally planned to cover a twelve-month period. However, in practice they spanned a twenty-month period.

In the first year of activities, technical assistance for developing and implementing operations research was provided by two FRONTIERS advisors and three national consultants. By the end of the year, consultants were contracted only for specific activities. Each organization required an average of 23 days of technical assistance, not counting the days used for teaching in workshops.

In collaboration with PROCOSI, FRONTIERS conducted four training workshops on design of operations research projects, qualitative research methods, utilization and dissemination of research results, and preparing research reports. Technical assistance on other topics, such as developing research instruments, creating databases, and using EpiInfo for transcribing and analyzing data was provided on-site to each organization. Workshop costs were shared with PROCOSI.

The operations research projects implemented by the organizations addressed a series of topics that can be grouped in two major categories: a) strategies for increasing access to and quality of reproductive health programs, and b) adolescents.

In the first category, four organizations tested provider training and on-the-job training and supervision systems as strategies for improving the quality of reproductive health services. Another three organizations focused on community interventions, such as using job-aids to identify unmet needs for reproductive health services, systematizing procedures for home visits and offering contraceptive group counseling. Finally, two organizations addressed more specific topics. One tested a system of pre-payment for hospital services provided at the time of childbirth, and the other tested the effects of counseling men in the use of family planning services.

Seven organizations focused their research on adolescents. Two of them conducted diagnostic studies; one aimed at improving the strategy of peer training, and the other at better understanding the needs of schoolteachers in relation to teaching sexuality-oriented topics to their students. The other five tested various training modalities in sexual and reproductive health for adolescents. One organization also tested training of pharmacy dependents as a means to improve the quality of services provided to adolescents. 
In general, study results showed that interventions improved the quality of services and reduced unmet needs in reproductive health. However, most of the studies concluded that the processes initiated were not sufficient, and that the strategies tested should be maintained for longer periods of time to achieve higher levels of quality.

Organizations conducting diagnostic studies on adolescents obtained important results for better understanding the dynamics of peer training and the strengths and weaknesses of teachers for providing sexuality education to their students. Other training programs in sexual and reproductive health tested in other studies showed significant improvements regarding knowledge and favorable attitudes toward self-health care.

Along with PROCOSI and FRONTIERS, the organizations that implemented the projects, are utilizing the research findings. Various strategies used in the research projects are being replicated by other organizations. For example, findings from one investigation are being used as input to Bolivia's Ministry of Education in developing the national curriculum for teacher training in sexuality. PROCOSI, for its part, has developed a catalogue of successful experiences that it is trying to replicate in its affiliated organizations. Furthermore, it is establishing an assistantship program through which personnel from an organization successfully implementing a given strategy can then train personnel from other interested organizations.

The experience of this collaborative PROCOSI/FRONTIERS project was very positive: high-quality research projects were carried out; programs benefited from the research projects; and a group of technicians was formed that with a small amount of help will be able to conduct new research projects from a managers' perspective.

The greatest difficulties in implementing the project were related to the limited time researchers had available and their need to accommodate specific research activities around their normal program activities. For FRONTIERS, the fact that 16 research projects were carried out simultaneously in diverse parts of the country affected the intensity of the technical assistance it would have liked to have provided.

\section{LIST OF ABBREVIATIONS}




\begin{tabular}{|c|c|}
\hline APSAR & $\begin{array}{l}\text { Asociación de programas de salud del área rural } \\
\text { (Association of health programs in rural areas) }\end{array}$ \\
\hline CEMSE & $\begin{array}{l}\text { Centro de multiservicios educativos } \\
\text { (Center of educational multiservices) }\end{array}$ \\
\hline CEPAC & $\begin{array}{l}\text { Centro de promoción agropecuaria campesina } \\
\text { (Center of rural women's agricultural promotion) }\end{array}$ \\
\hline CETM & $\begin{array}{l}\text { Centro de estudios y trabajo de la mujer } \\
\text { (Center for women's studies and work) }\end{array}$ \\
\hline CIES & $\begin{array}{l}\text { Centro de investigación, educación y servicios } \\
\text { (Center for research, education and services) }\end{array}$ \\
\hline $\mathrm{CPC}$ & $\begin{array}{l}\text { Centro para programas de comunicación } \\
\text { (Center for communication programs) }\end{array}$ \\
\hline CSRA & $\begin{array}{l}\text { Consejo de salud rural andino } \\
\text { (Andean rural health council) }\end{array}$ \\
\hline ENDSA & $\begin{array}{l}\text { Encuesta nacional de demografía y salud } \\
\text { (National demographic and health survey) }\end{array}$ \\
\hline HIV & Human immunodeficiency virus \\
\hline IEC & Information, education and communication \\
\hline IUD & Intrauterine device \\
\hline MSPS & $\begin{array}{l}\text { Ministerio de Salud y Previsión Social } \\
\text { (Ministry of Health and Social Security) }\end{array}$ \\
\hline NGOs & Non-governmental organizations \\
\hline OR & Operations research \\
\hline PAP & Papanicolau \\
\hline PCI & Project Concern International \\
\hline PER & $\begin{array}{l}\text { Programa educativo por radio } \\
\text { (Educational radio program) }\end{array}$ \\
\hline PROCOSI & $\begin{array}{l}\text { Programa de coordinación en salud integral } \\
\text { (Coordination program in integral health) }\end{array}$ \\
\hline PROMUJER & $\begin{array}{l}\text { Programas para la mujer } \\
\text { (Women's programs) }\end{array}$ \\
\hline RH & Reproductive health \\
\hline SACOA & $\begin{array}{l}\text { Servicios de asesoría a comunidades agrarias } \\
\text { (Consultation services for agricultural communities) }\end{array}$ \\
\hline SCF & Save the Children Federation \\
\hline SEDES & $\begin{array}{l}\text { Servicio departamental de salud } \\
\text { (Local health service) }\end{array}$ \\
\hline STIs & Sexually transmitted infections \\
\hline VSC & Voluntary surgical contraception \\
\hline
\end{tabular}




\section{BACKGROUND}

The Programa de Coordinación en Salud Integral (PROCOSI) is a network of 24 nongovernmental organizations (NGOs) in the health and community development sector in Bolivia. The PROCOSI Executive Secretariat implements the technical and administrative coordination of its members to increase their impact and sustainability. PROCOSI had a 1999-2001 budget of US \$200,000 for operations research (OR) and wished to conduct a program of small grants for operations research projects implemented by its affiliates. FRONTIERS agreed to provide technical assistance for the design of this small grants program, as well as for the implementation of the operations research projects.

FRONTIERS helped PROCOSI conduct an OR Workshop for its affiliates and a few consultants in La Paz from September 27 to October 1, 1999. Three FRONTIERS staff members and one staff member from Georgetown University participated as instructors in the workshop. They reviewed the conceptual, methodological and practical issues associated with this type of research and helped participants to write a draft project proposal relevant for their institutions. Sixteen draft project proposals were outlined during the workshop and presented orally and in writing. The staff of PROCOSI's affiliates produced fourteen of them, and PROCOSI staff produced the other two. Participants were given until November 15 to finalize their project proposals and submit them for funding to PROCOSI. Three Bolivian consultants were hired to help participants complete their proposals. Fourteen proposals were presented for funding. Of these, the operations research committee only approved six for presentation to PROCOSI management. The management committee met in January 2000 and approved funding for all six-project proposals. Six new proposals were approved for presentation to the management committee in their meeting on February 28, 2000.

PROCOSI then invited nine NGOs that did not participate in the operations research workshop to develop proposals and participate in the OR program. These NGOs agreed to develop one or two joint proposals in which all participants would develop the same type of projects. To assist in the development of joint proposals, organizations with similar programs and problems were identified. Thus, CARITAS and SACOA were invited to develop a proposal for assisting rural health promoters in identifying the unmet needs in reproductive health experienced by inhabitants of their communities. Save The Children Canada and PER were invited to work on educational programs for adolescents.

During the course of preliminary conversations, SACOA decided not to participate, and Save The Children Canada delegated its participation to CETM, one of its affiliates. PER, for its part, decided to take advantage of the research opportunity to test a semiindependent modality of adolescent training. Due to differences in ideas and the lack of similarities in the programs of interested NGOs, it was not possible to move ahead with the idea of joint research projects; thus, organizations opted to develop their own proposals.

Between April and September 2000, four new proposals were developed. CARITAS of Bolivia in April; PER and APSAR in August; and CETM in September. PER was a special case since it did not have a reproductive health program in place, but wanted to test out a 
new methodology in sexual health training. To move ahead with its idea, it was necessary to negotiate with the Save The Children Federation (SCF), which had a well-structured program with adolescents, so it would implement the strategy to be developed by PER. The four new proposals were approved by PROCOSI's management committee for funding.

\section{OBJECTIVES}

The objectives of this project were:

- To provide technical assistance to PROCOSI affiliates in the implementation of OR projects approved by PROCOSI's management committee;

- To develop one or two additional project proposals with PROCOSI members currently not participating in the operations research program;

- To conduct workshops and courses on OR themes related to the implementation of the projects conducted by PROCOSI affiliates;

- To repeat the process (workshop, proposals, technical assistance to projects) if funding was made available at the end of this first cycle of activities.

\section{ACTIVITIES}

\subsection{Technical assistance for implementation of OR projects}

A total of 16 PROCOSI organizations received technical assistance for implementing their operations research projects. Participating organizations and the projects carried out are shown in Table 1.

Table 1 1. CARE
PROCOSI organizations and operations research projects conducted Implementation of a training/supervision model, for improving quality of services 


\begin{tabular}{|c|c|}
\hline $\begin{array}{l}\text { 2. Centro de Multiservicios } \\
\text { Educativos (CEMSE) }\end{array}$ & $\begin{array}{l}\text { Affectivity, sexuality, and sexual and reproductive } \\
\text { health for teachers at secondary schools in La Paz }\end{array}$ \\
\hline $\begin{array}{l}\text { 3. Centro de Promoción Agropecuaria } \\
\text { Campesina (CEPAC) }\end{array}$ & $\begin{array}{l}\text { Development and testing of a strategy for family } \\
\text { planning services in line with interests of the rural } \\
\text { population in Santa Cruz }\end{array}$ \\
\hline $\begin{array}{l}\text { 4. Centro de Investigación, Educación } \\
\text { y Servicios (CIES) }\end{array}$ & $\begin{array}{l}\text { Results of standardizing contents in training } \\
\text { for adolescent leaders, in terms of quality of } \\
\text { educational sessions }\end{array}$ \\
\hline $\begin{array}{l}\text { 5. Consejo de Salud Rural Andino } \\
\text { (CSRA) }\end{array}$ & $\begin{array}{l}\text { Home visits following a specific protocol, to } \\
\text { reduce the unmet demand for contraception in } \\
\text { Montero }\end{array}$ \\
\hline 6. Esperanza Bolivia & $\begin{array}{l}\text { Evaluation of impact of quality of care on the use } \\
\text { of sexual and reproductive health services }\end{array}$ \\
\hline 7. San Gabriel Foundation & $\begin{array}{l}\text { Effects of introducing a loan and prepayment } \\
\text { system on the demand for hospital services }\end{array}$ \\
\hline 8. NUR University & $\begin{array}{l}\text { Diagnostic study on adolescents' attitudes } \\
\text { regarding peer education on topics of sexual and } \\
\text { reproductive health }\end{array}$ \\
\hline 9. Pro & $\begin{array}{l}\text { Strategies for contributing toward an increase in } \\
\text { the use of contraceptive methods in government } \\
\text { health services }\end{array}$ \\
\hline 10. Pro Mujer & $\begin{array}{l}\text { Effects of a training and supervision strategy in } \\
\text { counseling services on sexual and reproductive } \\
\text { health }\end{array}$ \\
\hline 11. Save The Children Federation & $\begin{array}{l}\text { Pharmacies as primary providers of orientation and } \\
\text { suppliers of contraceptive methods for adolescents }\end{array}$ \\
\hline 12. Servir & $\begin{array}{l}\text { Evaluation of the effects of an IEC strategy on } \\
\text { sexual and reproductive health in adolescents in } \\
\text { Caranavi }\end{array}$ \\
\hline 13. CARITAS Bolivia & $\begin{array}{l}\text { Detection of the population's reproductive health } \\
\text { needs, and monitoring of the activities and abilities } \\
\text { of health promoters }\end{array}$ \\
\hline $\begin{array}{l}\text { 14. Asociación de Programas de Salud } \\
\text { del Area Rural (APSAR) }\end{array}$ & $\begin{array}{l}\text { Effects of a training program addressing men on } \\
\text { the demand for contraception services }\end{array}$ \\
\hline $\begin{array}{l}\text { 15. Save The Children Canada Centro } \\
\text { de Estudios y Trabajo de la Mujer } \\
\text { (CETM) }\end{array}$ & $\begin{array}{l}\text { Incorporation of a gender perspective in adolescent } \\
\text { sexuality training }\end{array}$ \\
\hline $\begin{array}{l}\text { 16. Programa Educativo por Radio } \\
\text { (PER) }\end{array}$ & $\begin{array}{l}\text { Educational advantages of interactive methodology } \\
\text { using audiocassettes on gender issues directed at } \\
\text { adolescents }\end{array}$ \\
\hline
\end{tabular}

Although the 16 operations research projects were carried out, two organizations (CEPAC and CIES) had not yet turned in their final reports at the time of the writing of this report. 
Each operations research project had a budget of approximately US $\$ 10,000$. These funds were provided by PROCOSI.

The research projects conducted can be grouped under five topics:

1. Quality of services: 4 projects

2. Community interventions: 3 projects

3. Forms of payment for hospital services: 1 project

4. Involvement of men in reproductive health programs: 1 project

\section{Adolescents: 7 projects}

Technical assistance for implementing the studies was provided by the Population Council national advisor and three national consultants. Eight months after the projects were initiated, a FRONTIERS fellow, Patricia Riveros, based in La Paz joined the team. From project design to final report writing, the average time dedicated to giving personalized technical assistance for each participating organization (without considering workshops) was 23 days, for a total of approximately 368 days. Each of the consultants dedicated an average of 33 days, and the rest of the time was covered by the FRONTIERS team.

To carry out the research projects, each organization named one or two persons to be the researchers responsible for the study. During the entire project period, these researchers participated actively in training events and were responsible for implementing activities.

Technical assistance was provided using a number of modalities: a) FRONTIERS personnel and consultants traveled to researchers' work sites, where the projects were taking place; b) training workshops were held to provide assistance in carrying out the research projects, as described in the corresponding section; c) electronic mail was used and was the means of communication most used during the review of materials and instruments; d) time was dedicated to reviewing and editing periodic and final reports (this phase of technical assistance required more time than expected, since it was necessary to review everything from methodological consistency in the studies, to correct grammatical writing in reports); and e) during the entire research project period, materials on research projects being conducted by Population Council and other organizations was disseminated, thus contributing to keeping researchers and program managers up to date.

The process of preparing final reports was complemented by two workshops for training researchers in: a) interpreting data, and the writing and format for research reports; and b) preparing effective presentations of research findings, in terms of enhancing the use of the strategies tested. Based on these activities, researchers wrote preliminary reports that were sent to FRONTIERS, where an initial editing process took place. Improvements in both the presentation, as well as analysis of findings, were made through ongoing consultation with 
researchers. As soon as the contents were agreed upon, each report was sent to a printer for final review.

While PROCOSI's technical assistance project was originally planned for a twelve-month period, the actual duration was 20 months, since most of the organizations were unable to implement activities according to their timelines and more than half of them requested no cost extensions for periods of time varying between three and six months.

\subsection{Training in selected OR themes}

In addition to field training on topics such as the use of the EpiInfo packet, and the development, testing and application of research techniques and instruments, workshops were given on the following topics:

Designing operations research projects (October 1999): The initial activity described in the background section.

Qualitative research methods (June 2000): Workshop given by two national facilitators, who are experts on this topic, and a consultant from Peru who presented the simulated client technique. Due to the costs involved in transporting participants from to La Paz and the negative impact on services when operations personnel leave their areas, this workshop (and the following ones described below) was carried out at different times in two different regions of Bolivia, first in $\mathrm{La} \mathrm{Paz}$, attended by participants from the country's western region, and then in Santa Cruz, for participants in the eastern region. There were approximately 14 participants (one or two per organization) at each two-day workshop.

Use of research findings (May 2001): Due to the importance of promoting the use of operations research findings, a replica of the workshop conducted annually by Population Reference Bureau in Costa Rica (attended by the FRONITERS National Advisor) was conducted, using the same materials and methodology. This activity was carried out over a three-day period in both La Paz and Santa Cruz. For this workshop, technical assistance was provided by a person from the Centro para Programas de Comunicación, formerly linked to JHU/PCS.

Preparing research reports (June 2001 and September 2001): Having detected the difficulties experienced by participating researchers in the areas of analysis, interpretation and research report writing, a workshop was prepared for the purpose of helping them through these aspects. Two-day workshops were facilitated by the FRONTIERS National Advisor and Fellow. Unlike other workshops, these were not held on a regional level and the levels of progress made in the individual research projects were taken into consideration. Thus, the seven organizations that were in the final phase of their projects in June participated in the first workshop, while the other nine organizations participated in the second workshop held three months later. Both workshops took place in La Paz.

Workshop costs were shared by FRONTIERS and PROCOSI. While FRONTIERS covered all expenses related to facilitators and workshop materials, PROCOSI took 
responsibility for transportation costs, lodging and meals for participants. Coordination of activities for the workshops and technical field assistance was carried out through the PROCOSI Executive Secretariat, facilitating the completion of activities to a great degree.

Finally, FRONTIERS provided technical assistance for organizing and developing other training events, such as a workshop sponsored by the National Research Committee on the use of research findings, and sponsored, together with the World Health Organization, a seminar on Evidence-Based Medicine.

\subsection{Second round of PROCOSI's operations research program}

PROCOSI is interested in continuing cooperative efforts with FRONTIERS. The experience of the participating organizations has been satisfactory and they now have personnel who have concluded an initial cycle of operations research projects. A second cycle would help to consolidate skills and knowledge, increasing the possibility of institutionalizing OR in the corresponding programs. PROCOSI has included a budget item for carrying out operations research with assistance from FRONTIERS in new project proposals presented to donor agencies such as USAID and the Kellog's Foundation.

\section{RESULTS}

The general description of findings obtained in operations research projects, as well as normative implications and recommendations for their use, are presented below by topic area. Summaries of projects that addressed strategies for increasing access to and quality of reproductive health services are included in the Appendix 1. Summaries of projects dealing with reproductive health services for adolescents are presented in Appendix 2

\subsection{Strategies for increasing access to and quality of reproductive health programs}

One of the most widespread problems confronted by organizations working in Bolivia is the minimal access to and quality of services in their reproductive health programs. This is true for both public institutions and non-governmental organizations. For NGOs, failure to fulfill the goals established in their programs leads to a series of consequences, affecting commitments with their funding agencies and expectations of beneficiary populations, as well as the programs' impact on the health of the more vulnerable populations. Therefore, the goal of many of the research projects carried out was to improve the quality of services and increase the demand for services, with some of them testing out training and follow-up strategies, others attempting to increase the demand for services in communities, and still others attempting to have an impact on both areas.

In the group of research projects linked to quality of services, we included those carried out by PCI, Esperanza, CARE and ProMujer. Among those carrying out community interventions are CARITAS and CSRA. The San Gabriel Foundation tested payments for hospital services, and APSAR tested strategies for involving men in reproductive health programs. 


\subsubsection{Quality of services}

Four organizations tested different strategies for training providers; all of them were accompanied by training supervision activities. Also, PCI worked with health providers and community leaders, structuring a system of home visits that would permit promoters to identify unmet needs in reproductive health, and to then pass this information on to health service providers.

Training activities followed different modalities:

- PROMUJER held a two-day workshop in which both professional health personnel and community promoters participated. This workshop was followed by a series of three training supervisions, which allowed researchers to identify weaknesses and provide corresponding feedback.

- PCI used results from simulated client visits to give feedback to service providers after each of three workshops on quality of care for health personnel. Each new workshop began with a presentation of the observations from simulated clients. Based on this information, areas requiring more training were detected, as well as the points of resistance on the part of providers to adopting certain recommendations and norms.

- ESPERANZA Bolivia tested a quality-improvement model that was based on first satisfying the expectations of internal clients (providers), then working toward the satisfaction of external clients (consumers of services). Emphasis was placed on training in technical aspects of different clinical procedures, such as prenatal services and administering the Papanicolaou test, and also interpersonal relationships among team members and between team members and service users. Along with this focus, a committee was formed for improving quality, which included community members who were given the responsibility of monitoring providers' activities and commitments.

- CARE tested the effectiveness of an ongoing training supervision model that it had been using for two years. The research project was therefore an opportunity to test the procedure, and decide whether or not to institutionalize it.

These four research projects demonstrated the effectiveness of interventions in terms of increasing providers' knowledge and adopting better practices. However, it also became apparent that training does not achieve all the expected results on its own, and that these activities, accompanied by training and supervision, should be institutionalized and used for prolonged periods of time. Also, it became evident that external factors, such as the high turnover rate among personnel, as well as deeply rooted prejudices, make it difficult to establish good quality services.

Another problem often observed was that, despite obtaining statistically significant results in improving certain variables in comparison with a control group, the resulting level was still very low. An example of this was when health personnel's knowledge of contraceptive technology improved significantly in comparison with the control group, but the proportion 
of providers who had an appropriate level of knowledge was still less than 40 percent in the experimental group. This suggests the need for more competency-based training.

In all cases in which measurements were made, significant increases were observed in the satisfaction of service users. It is especially noteworthy, however, that the levels of satisfaction declared by users were already high before the interventions took place ( $>$ $85 \%)$.

\subsubsection{Community interventions}

Two organizations focused on community interventions:

- CARITAS of Bolivia works in a remote rural area where accessibility is a problem. Its main strategy for providing services is to periodically move its mobile health team from one location to another. CARITAS had observed, however, that the yields produced by this mobile team, and therefore, the number of inhabitants receiving reproductive health care, were unacceptably low. It decided to develop a segmentation instrument to assist health promoters in identifying the unmet needs in the communities served. As soon as promoters had been trained to use these segmentation forms, the demand for contraceptive counseling services increased by 400 percent, and it was especially noteworthy that three times more men than women asked for this service. The number of women who received anti-tetanus shots was another variable positively impacted by the intervention (increasing by $35 \%$ in relation to the pre-intervention assessment). However, the demand for other services, such as prenatal care, childbirth care by trained personnel, and STI treatment, was not affected.

- The Consejo de Salud Rural Andino based its intervention strategies on a census of its beneficiary population that was updated annually. Information from the last census had demonstrated a serious unmet need for contraceptive methods and indicated that nearly half of the couples that said they used the calendar rhythm method did not know when the woman's fertile period takes place. To resolve these problems, a home visit model was tested in which, if one of the two problems mentioned was detected, providers would offer contraceptive counseling and/or training in correctly using the rhythm method. Despite methodological problems, preventing any firm conclusive findings from this research, it was observed that the home visits decreased the unmet need for contraception (10\% adopted a modern method and $42 \%$ a natural method).

\subsubsection{Forms of payment for hospital services}

The San Gabriel Foundation tested a system of prepayment for hospital services in order to increase users' economic accessibility to these services, as well as to favorably impact the hospital's financial sustainability. In this prepayment system, called "Plan Cigüeña" (Stork Plan), users paid fixed amounts at prenatal care appointments, so as to fully pay for childbirth services by the time they were required. This innovation was accompanied by an 
IEC campaign (fliers, posters and radio segments) to inform the public of this new way to access hospital services.

The results demonstrated that access to childbirth services was facilitated for women who otherwise would not have been able to pay the amount of money required. Nevertheless, an event outside the project's control affected the results. The Ministry of Health stepped up implementation of basic health coverage offering free childbirth services in public hospitals, which likely played a part in the fact that there was not a significant increase in the demand for childbirth services at the San Gabriel Foundation hospital. Since the demand for RH services did not increase significantly, hospital income did not increase either and there was no effect from the intervention on financial sustainability. What would have happened if the credit offer had not been made was not studied. It is possible that hospital income would have decreased instead of remaining at the same level, in which case it would have been possible to attribute the intervention with having a beneficial effect.

\subsubsection{Involvement of men in reproductive health programs}

APSAR, located in Cochabamba, proposed the hypothesis that the low demand for contraceptive methods in the area where it is working was due to opposition on the part of men to the use of any methods, and that this attitude was based on a lack of knowledge. To test this hypothesis, the organization developed a training curriculum in reproductive health designed specifically for men. Through agreements with men's labor unions, especially in the transportation and agriculture sectors, a series of educational and sensitization sessions were held on this topic. The educational intervention was complemented by a process of improving the quality of services in local establishments, to assure that when men were motivated by the training to seek services, establishments would be prepared to offer those services. EngenderHealth provided technical assistance for this component.

Data obtained from local health establishments showed a very significant increase in the demand for contraceptive counseling services (ten times greater than before the intervention) for both men and women. The number of new contraceptive users also increased by 86 percent. However, the increase also occurred in similar proportions in the control group, an effect that could have been caused by the intervention carried out in local establishments or by contamination of the control group. The particular contraceptive methods chosen were also modified after the intervention, with a decrease in the number of condom users and an increase in the number of women using various modern methods, especially Depo-Provera and IUDs.

Results obtained in this research project are not conclusive, revealing the minimal amount of knowledge we have with regard to the dynamics in couple relationships and the effects of interventions focused on men.

\subsection{Adolescents}


Adolescence is the stage of life that signals a transition to adulthood. What takes place between 10 and 19 years of age tends to determine the way in which these young people will live when they are adults, not only in terms of their sexual and reproductive lives, but also in terms of their entry into social and economic life.

In most Latin American countries, adolescents represent a significant portion of the population. In Bolivia, adolescents make up 23 percent of the country's total population. Adolescence is a stage during which serious health problems do not generally occur. However, in relation to sexual and reproductive health, young people are especially vulnerable to unwanted pregnancies, unsafe abortions, and contracting sexually transmitted infections and HIV. According to data from the last National Demographic and Health Survey, pregnant adolescents constitute 21 percent of all pregnant women. Fourteen of every 100 women between 15 and 19 years of age are already mothers or pregnant with their first child, and the percentage increases to 30 percent by 19 years.

Various studies (e.g. IMIFAP, 1993) have demonstrated that training can increase adolescent's knowledge about contraception and can increase the possibility that sexually active youth will use contraceptives in their sexual relations. The incorporation of the gender perspective and the development of abilities in negotiating and communicating, among others, have shown to be useful elements in promoting care for one's sexual and reproductive health.

Six PROCOSI organizations focused on adolescents in their research projects. These projects included: a) two diagnostic studies, one by NUR to learn about young people's attitudes regarding peer education, and the other by CEMSE to evaluate the knowledge and attitudes of teachers with respect to teaching sexuality in schools; b) three studies testing alternative methods of sexuality training: PER used audio cassettes, SERVIR studied the effects of an IEC campaign, and CETM, in Cochabamba, tested the incorporation of a gender perspective in educational curriculums on sexuality; and c) Save The Children used strategies for involving personnel in private pharmacies to provide quality services in orientation and contraceptive methods for sexually active adolescents. The target populations for the six research projects were male and female adolescents between 10 and 19 years of age and attending school. Four of these studies were conducted in urban areas and two in rural areas.

\subsubsection{Diagnostic research projects}

The NUR University includes, as part of its community outreach activities, an educational program on sexuality for addressing adolescents in schools in the city of Santa Cruz. One of the strategies used is peer training. Its research project sought to discover the appropriate characteristics for adolescents serving as peer instructors in order for training to be more effective and to discover perceptions of adolescents with regard to this form of training.

Information was gathered through focus groups, in-depth interviews and a self-applied questionnaire. The results showed that young people expected their peer educators to be 
trustworthy persons, who maintained the confidentiality of the information they received from other adolescents, and were serious and preferably older. They also said they would not confide their problems to young people of the same age, and would rather turn to their mothers or older friends if they need answers or advice. The questionnaire on knowledge and attitudes revealed that many adolescents have mistaken or biased concepts related to sexuality.

The goal of the study conducted by CEMSE in the city of La Paz was to explore the knowledge, attitudes and educational practices of teachers in public schools, in relation to topics of sexuality and affectivity. The expectation was that based on this diagnostic study it would be possible to develop a training curriculum for teachers, with the understanding that they would be responsible for training students on this topic.

The research project revealed that only 42 percent of the teachers had received some formal training on the orientation of youth, and that this knowledge came from their own experience and from reading books related to this topic. The age of the teachers was an important variable in exploring their willingness to talk about sexuality with their students. Teachers between 24 and 35 years of age were the most willing to do so as part of their professional role. With an acknowledgement from the Ministry of Education, CEMSE has presented the results of this research project in a book format, and they are being used in the development of an official national curriculum on sexuality.

\subsubsection{Sexuality training}

One of the strengths of the PER organization is producing educational materials in audiocassettes. A problem frequently confronted by organizations that work with training adolescents, and use workshops as their methodology is the limited scope of their beneficiary populations. According to didactic criteria, no more than 25 persons should participate in a single workshop, since otherwise the participation of those in attendance diminishes and so does the workshop's effectiveness. However, in line with cost-effective criteria, programs for adolescents tend to have beneficiary populations made up of thousands of adolescents.

To contribute toward resolving this problem, PER proposed a methodology for sex education based on audiocassettes. The hypothesis was that this methodology would have a level of effectiveness similar to direct participation in workshops, but at a lower cost and with a greater possibility for reaching more adolescents in less time.

The results indicated that although the effectiveness (in terms of increase in knowledge) was 15 percent lower than for workshops, the cost was 47 percent lower and therefore, the possibility of providing training to more adolescents was greater.

The research project carried out by SERVIR took place in a rural area in the La Paz department. The provider intervention was aimed at improving the quality of services from providers at hospitals and SERVIR's health center, and from personnel at private 
pharmacies in the area. The client intervention consisted of a series of educational sessions on sexuality conducted with students at two schools.

The training at schools significantly increased knowledge and positive attitudes toward preventing pregnancies and STIs. And, using the simulated client technique, it was shown that the quality of attention in pharmacies and at health establishments also improved.

CETM, an organization affiliated with Save The Children Canada, tested incorporating a gender perspective in sexuality training. Also, to make training sessions entertaining, a series of interactive games was developed.

Incorporating the gender topic attracted adolescents' attention and revealed a series of prejudices that adolescents have with regard to male and female roles in the areas of sexuality and reproduction. The greatest merit of the educational intervention was having introduced the topic as something to think about, since for most of the adolescents, this was the first time they had thought about the ways that gender roles affect their lives and futures. The results demonstrated positive changes in both knowledge and attitudes, but also revealed the need to incorporate a gender perspective in training contents.

\subsubsection{Training for personnel at private pharmacies to improve quality of services}

The baseline for Save The Children Federation's "Making Decisions" program demonstrated that most adolescents who had used some type of contraceptive method had obtained it at a private pharmacy. In Bolivia, the personnel at private pharmacies had not previously been the focus of training programs for offering good quality services.

The operations research project conducted by Save The Children was designed to train the personnel at four private pharmacies in improving the quality of services, and to develop an IEC campaign that addressed adolescents, using the main slogan of "Pharmacies, your allies."

Visits by simulated clients to pharmacies showed that mistreatment and discriminatory treatment were not a frequent occurrence, but that they did occur. Further, little information was provided and serious demeanor embarrassed adolescents and obstructed their access to contraceptive orientation and methods.

After the intervention, the quality of services improved notably, with favorable changes observed in the attitudes of pharmacists, thus facilitating adolescents' access to contraceptive services. In the experimental pharmacies, the sale of contraceptive methods increased by four times, especially the sale of condoms, while in the control pharmacies, sales increased by 14 percent.

Despite the positive results obtained, there are still problems to address, since not all the methods approved by national health service delivery guidelines are available in the pharmacies, and pharmacists were observed to have a marked inclination toward offering the methods that were more lucrative for them. 
In light of the results obtained, Save The Children has incorporated training pharmacists as a regular activity in its program and is expanding the intervention to include 14 other pharmacies in the city of Oruro.

\section{DISSEMINATION AND UTILIZATION OF SUBPROJECT RESULTS}

In association with PROCOSI, FRONTIERS has developed a dissemination plan for the group of research studies included in this project. This dissemination plan extends beyond the project's closing date. As part of this plan, four research projects were presented at the USAID Bolivia audit in February 2002, attended by representatives of other USAID cooperative agencies and Ministry of Health personnel. Independently of this joint project, each organization has been disseminating the findings from its research. And even more importantly, some of the strategies tested are now being used in other areas from that of the original project and also by other organizations. This is the case in the intervention carried out by CARITAS, which tested segmentation instruments in La Paz, and is currently expanding the strategy to Oruro and Potosí. PER has received a formal request to assist Freedom From Hunger in the development of training contents with the audiocassettes methodology that PER proved to be effective. Save The Children has incorporated training for pharmacists as a regular part of its program.

The findings obtained by APSAR and CARITAS, with regard to involving men in reproductive health programs, have served as the basis for developing a new proposal for research in conjunction with EngenderHealth and PROSIN (Proyecto de Salud Integral), the latter of which is financed by USAID to provide technical and financial assistance to Bolivia's Ministry of Health.

In addition, CEMSE published its research in a book format and with support from Bolivia's Ministry of Education, it has been presented as a contribution to the development of a curriculum on sexuality for public school teachers.

\section{CONCLUSIONS}

This project revealed the high level of interest on the part of organizations affiliated with PROCOSI in carrying out operations research activities. Both the field training and workshops were very useful for participants, as can be noted from the workshop evaluations.

To fulfill the objective of institutionalizing operations research as a routine procedure, it is necessary to repeat the process at least a few more times. There are still some procedures and topics that were not addressed in an in-depth way in this first round and, in some cases, this made it difficult for researchers to conclude their studies.

The partnership between FRONTIERS and the PROCOSI network was very efficient, both because the coordination of events facilitated carrying out activities and implementation costs were shared, increasing the feasibility of moving ahead with this type of initiative. 
Implementation of the research projects required an investment of between US\$5,000 and $\$ 13,000$ per institution, an amount that was covered by PROCOSI. The major part of the investment was designated for paying varying percentages of the researchers' time and secondly, for the production of materials and research instruments. Also, PROCOSI's Executive Secretariat spent approximately US\$15,000 on traveling expenses for participants to attend workshops.

There were aspects of the research projects that were not addressed as deeply as desired, such as statistical analysis and data interpretation. This situation was due to the limited time available to researchers and the difficulties experienced by institutions when they were left without their personnel during the time trainings were held. In addition, PROCOSI has an annual training program on different topics that covers most of the calendar year, and any new training activities had to compete with those already on the calendar.

Most of the research projects followed high-quality methodological processes and many of them also had quasi-experimental designs. As in all research processes, there were problems, some related to the intensity and quality of intervention, and others with the application of research instruments and techniques. There were also some cases in which the sample was compromised or insufficient for reaching valid conclusions.

Lessons were learned from all the research projects and many of them showed beneficial effects for the programs and their users. Others revealed problems with services and providers. The majority concluded that the processes initiated, whether in training or supervision, should be ongoing processes that need to be institutionalized in order to achieve better results.

While most of the research projects demonstrated statistically significant changes in many of the variables studied, the meaning of this change on its own was deceiving since the progress made was far from the ideal. For example, there was a case in which 40 percent of the providers were able to carry out one procedure correctly and this represented a statistically significant improvement. However, in practical terms, this result signified that less than half of service providers implement the procedure correctly.

The major difficulty from the researchers' viewpoint was the lack of time to dedicate to the studies. Despite the interest expressed by most of them, other activities competed for their time. From FRONTIERS' viewpoint, the fact that 16 research projects were being carried out at the same time was a major obstacle and it had an impact on the quality and intensity of the technical assistance provided. Although two persons on FRONTIERS' staff were assisted by three other consultants, the technical team's capacity was insufficient to cover interventions taking place in different parts of the country at the same time.

One interesting observation that coincides with other research studies conducted in Bolivia that have not been published is the fact that enthusiasm gradually diminishes as the research project progresses. In most of the research projects, the initial phase was 
completed relatively quickly, but writing final reports was a slow process marked by many difficulties.

\section{APPENDIX 1}

\section{SUMMARIES OF ACCESS AND QUALITY PROJECTS}


Title:

Institution:

Researchers:

Promotion of Contraceptive Method Use at State Health Services

\title{
Project Concern International
}

\author{
Dr. José Luis Llanos Fernández \\ Ruth Bolaños Carreño
}

Project Concern International (PCI) is a non-governmental organization which works in two main areas: direct work with health providers, community leaders and promoters, and provision of training, supplies and technical assistance to the Ministry of Health and Social Prevision $(\mathrm{MOH})$ personnel. With the $\mathrm{MOH}$, PCI coordinates efforts in sexual and reproductive health, service promotion, and patient care and referral to the state service network.

In January 1999, in response to the population's demand for contraceptive methods, PCIPotosí started a sexual and reproductive health program with emphasis on family planning. Most of the inhabitants of the Potosí area live in extreme poverty.

In 1999, between the first and third quarters, the number of new contraceptive method users decreased by $44 \%$ in the areas where the project was implemented. Several factors could account for this drop: deficiencies in the quality of care provided by the Ministry of Health (Departmental Health Service - Potosí), lack of promotion and referral to sexual and reproductive health services, high job rotation at the Departmental Health Service (in Spanish, SEDES), and problems in filling out contraception service records.

Two strategies were designed to help improve service provision: training of health providers, and domiciliary visits and referrals to services. The intervention consisted of a training session and two reinforcement sessions for health providers, in sexual and reproductive health and interpersonal skills, and three rounds of domiciliary visits to inform women about important aspects of sexual and reproductive health and the health centers that provide services in this field.

The research used a quasi-experimental design with time series and no control group. Data were obtained from health facilities records, promoters' logs, and the simulated-client technique.

The training was provided to all health personnel currently working with PCI (25 SEDES providers from three health centers and five health posts, 21 health promoters, and 15 health leaders). Home visits were conducted in 10 urban zones, with the participation of 15 health leaders; and in 38 rural communities with 21 promoters.

Observations indicated that health workers provided information to users only about the condom, the pill, IUD, and injectables. After the training, the information about contraceptive methods included the rhythm method and, less frequently, vaginal tablets and female voluntary surgical contraception (VSC). Regrettably, the information provided was 
too general, overlooking issues related to the side effects or special care inherent in the use of each method.

Even after training, health providers did not inquire about the particular needs of the women or use the sessions to give additional information or carry out complementary tests such as Pap smear or breast examination.

\section{Figure 1. Result of applying the simulated client technique}

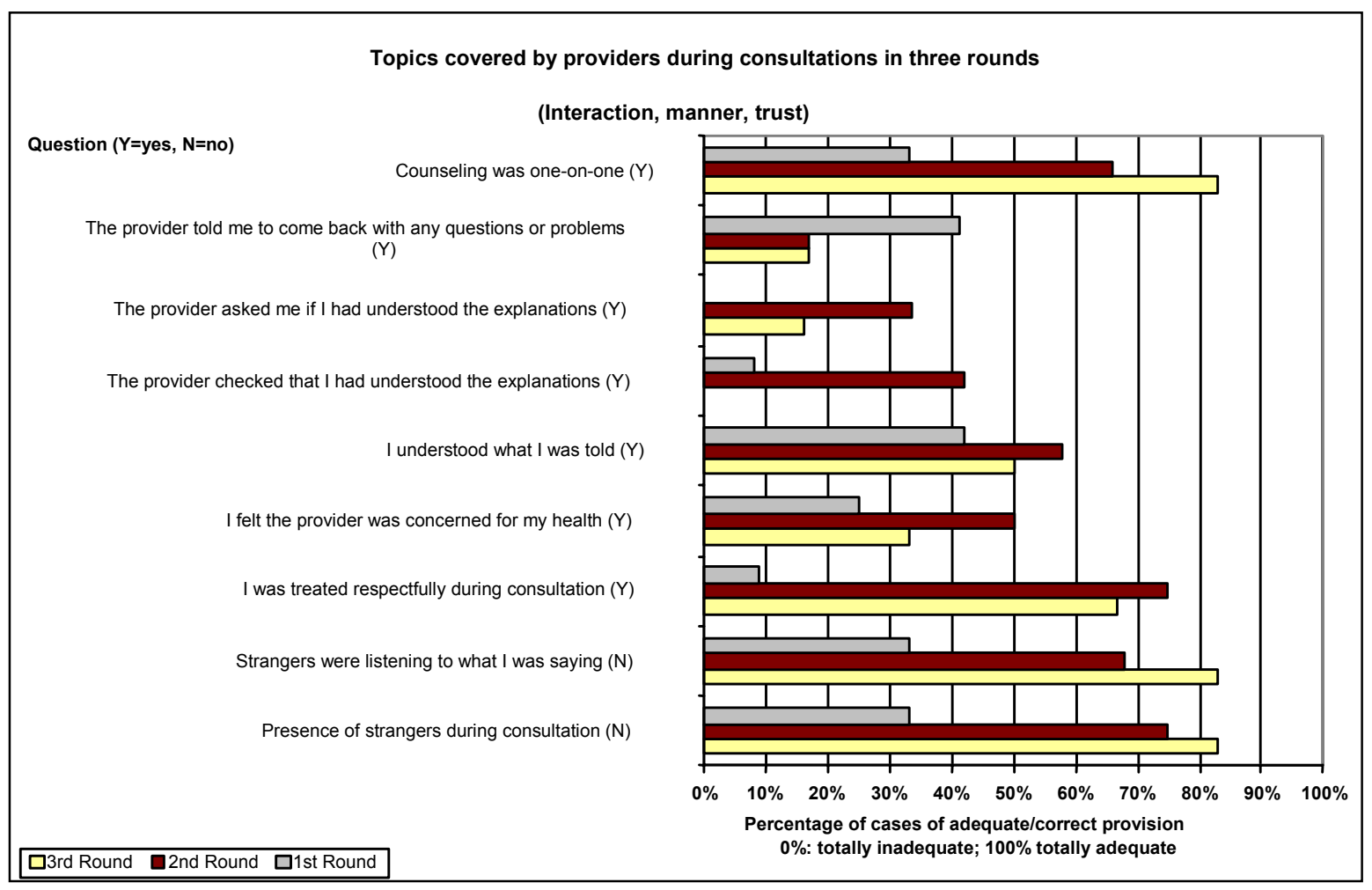

Providers' interaction, treatment, and trust at consultation improved considerably as a result of the training. However, instances of discrimination against age and ethnic group persisted (see Figure 1). 
Table 1. Results of the visits and referrals strategy

\begin{tabular}{|l|c|c|c|}
\hline Visit conducted & Referrals & $\begin{array}{c}\text { Presenting at } \\
\text { health center }\end{array}$ & $\begin{array}{l}\text { \% of referrals } \\
\text { presenting at } \\
\text { health center }\end{array}$ \\
\hline New users & 143 & 128 & $90 \%$ \\
\hline With four prenatal visits & 143 & 127 & $89 \%$ \\
\hline TT (1,2,3,4,5 doses) & 2.029 & 1.763 & $87 \%$ \\
\hline Repeated controls & 640 & 545 & $85 \%$ \\
\hline P.A.P. & 160 & 136 & $85 \%$ \\
\hline Counseling & 745 & 568 & $76 \%$ \\
\hline Continuous users & 28 & 21 & $75 \%$ \\
\hline $\begin{array}{l}\text { Active users } \\
\text { TOTAL }\end{array}$ & 194 & 141 & $73 \%$ \\
\hline $\begin{array}{l}\text { Pregnant women will have one prenatal } \\
\text { control visit }\end{array}$ & 465 & 334 & $72 \%$ \\
\hline $\begin{array}{l}\text { One prenatal control visit before the 5th } \\
\text { month of pregnancy }\end{array}$ & 230 & 129 & $56 \%$ \\
\hline \multicolumn{1}{|c|}{ TOT } & $\mathbf{4 . 7 7 7}$ & $\mathbf{3 . 8 9 2}$ & $\mathbf{8 1 \%}$ \\
\hline
\end{tabular}

The system of referrals and home visits has significantly improved the promotion and demand for sexual and reproductive health services. This is validated by the fact that 81 percent of the women who were visited at their households and received information about health centers later sought care at those facilities.

Based on the findings of this study, we recommend continuing the proposed strategies. To that end, agreements with various institutions or other mechanisms that allow guaranteeing sustainability of efforts should be implemented. Dissemination of results and findings at SEDES-Potosí, and at the Districts of Alonso de Ibáñez and Puna has been contemplated, so that this experience helps to strengthen the local health system, particularly sexual and reproductive health services. In addition, dissemination of results through the media and printed materials, reports and other channels is recommended. 
Title:

Institution:

Researchers:
Effects of a Training Program Focused on Men on the Demand for Contraceptive Services

\section{Association of Rural Health Programs (APSAR)}

\section{Susana Sánchez}

Kenia Ricaldi A.

In 2001, the Association of Rural Health Programs (APSAR) conducted an operations research study in four communities of the Sipe Sipe Municipality, in the Department of Cochabamba, Bolivia. These communities were chosen due to their low demand for sexual and reproductive health services, especially contraception. The objective of this study consisted in providing training in sexual and reproductive health to men living with a partner, in order to increase demand for contraceptive methods.

The study population consisted of 600 men, members of organized groups, with which a community-training program on sexual and reproductive health was developed. Simultaneously, health personnel of four facilities were trained to offer health services featuring premium quality and humane care, with a gender focus. The research followed a quasi-experimental design, which compared data from quantitative observations before and after the intervention, using an experimental and a control group.

The results of training men living with a partner show a significant improvement in their knowledge on contraceptive methods. Such improvement was measured by the men's ability to mention and describe the various methods promoted. Increased knowledge by partners in the Sipe Sipe Municipality was accompanied by greater demand for information and an increased use of contraceptive methods.

Figure 1. Number of Users by Group: Pre versus Post

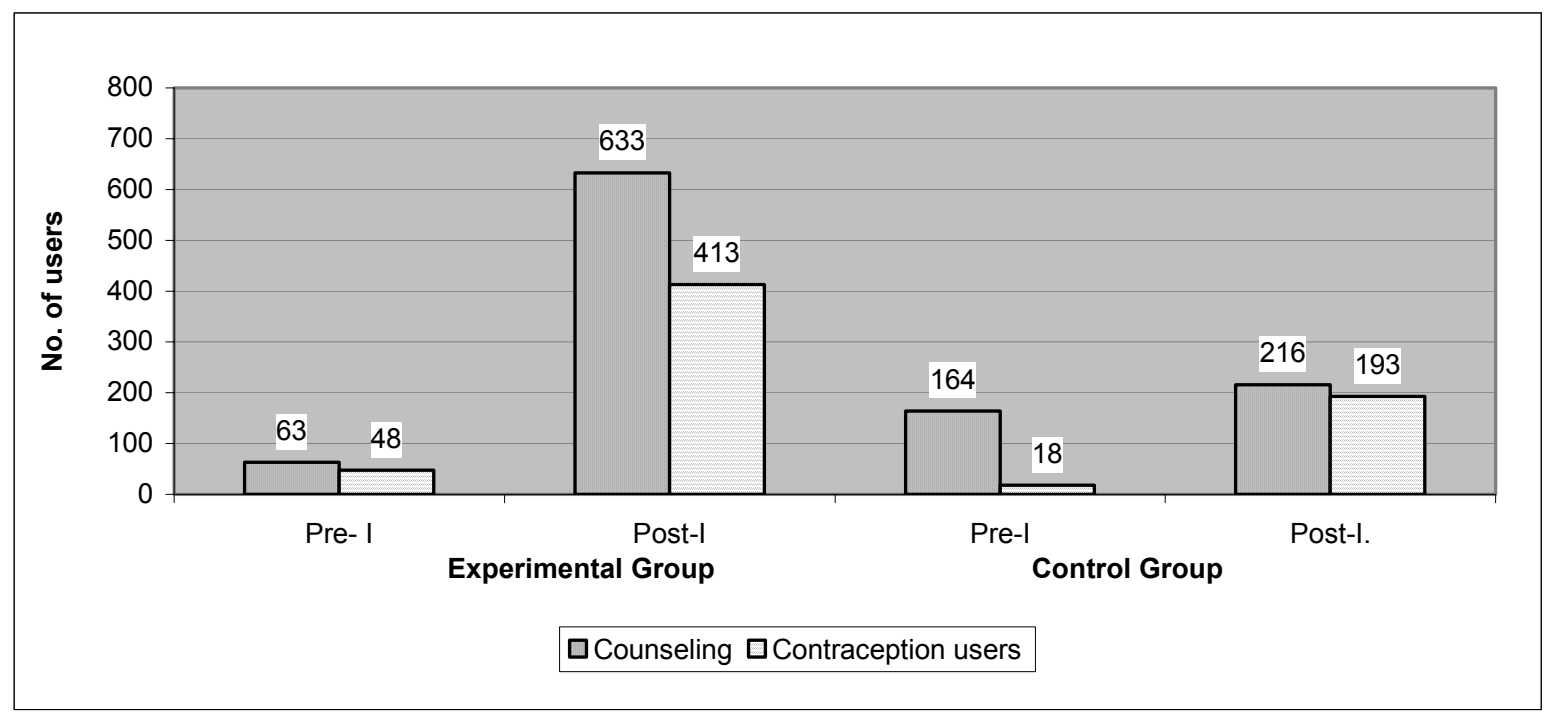


Regarding preferences for different methods, an increase in the number of users of the Intrauterine Device (IUD) and Depo Provera was observed. Additionally, use of traditional methods, such as rhythm and withdrawal, and the number of users of the condom for contraception purposes decreased.

Findings indicate that community interventions among men can increase the use of more effective contraceptive methods (transition from natural to modern methods). Likewise, a reduction in the number of condom users was noted, a result not sought by the project. These findings are in agreement with studies that reveal that male willingness to use contraception usually means that men are prepared to let their female partners use a method. However, this does not imply that men themselves will use them.

Several variables remained unchanged after the intervention, such as the individual exercise of sexual and reproductive rights. A strong conviction that reproductive ideals are a responsibility shared by the partner, and about birth spacing and use of contraceptive methods was noticeable. Alternatively, concerning general health matters such as seeking care for the sick child, the men assert that it is fundamentally a woman's responsibility.

Figure 2. Men's attitude towards their partners' right to decide to use a method

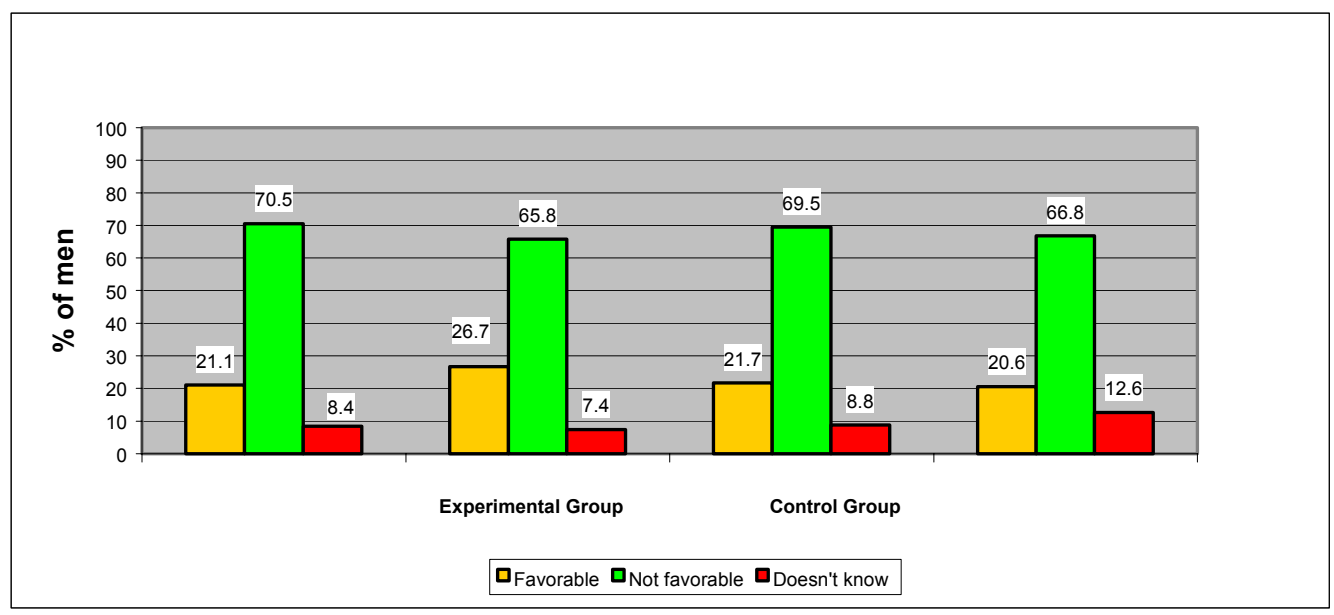


Figure 3. Men's attitude towards their partners' right to seek medical care without their permission

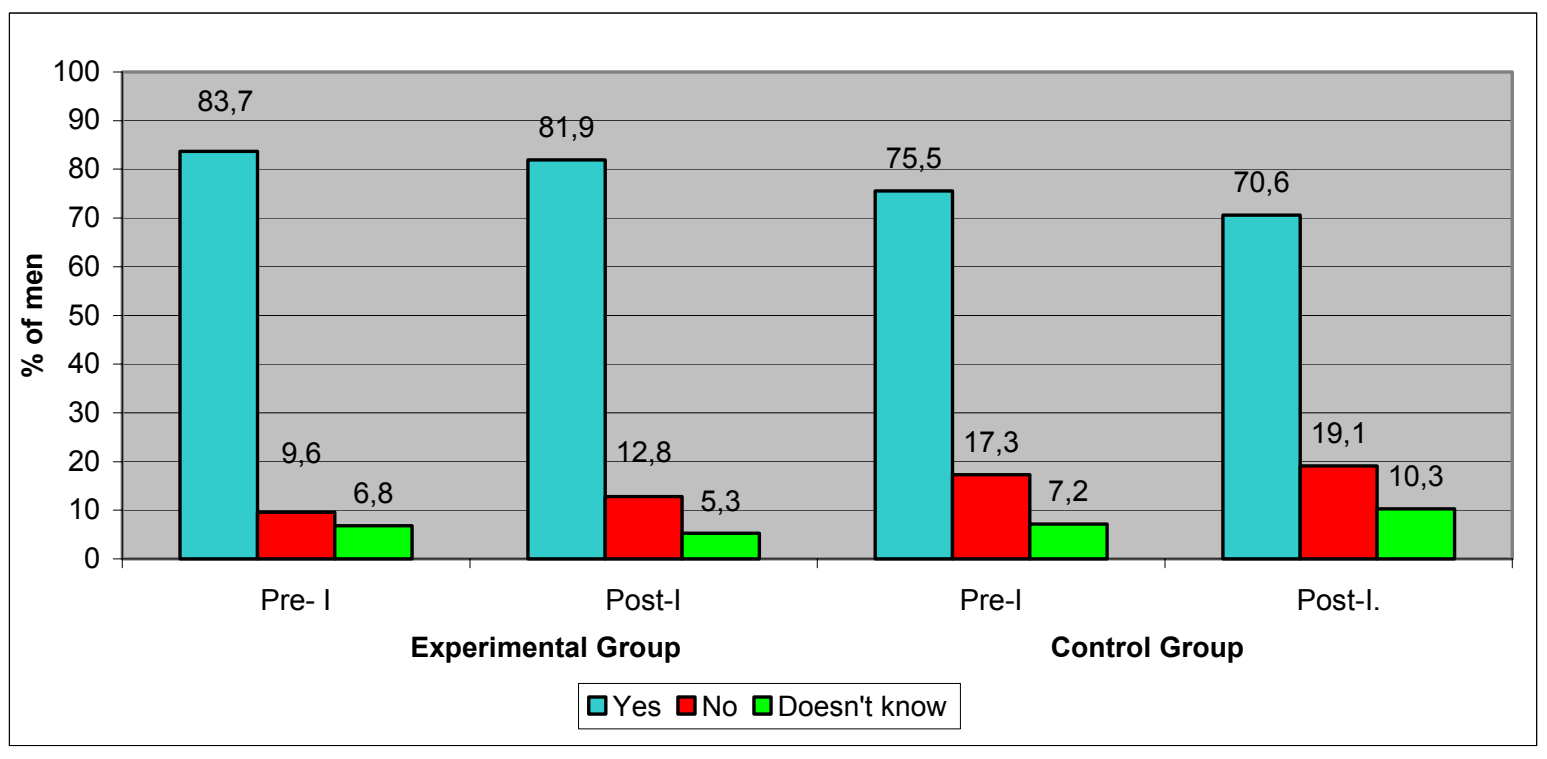

This study did not probe into the efficacy of service provision to men at health facilities. It is recommended that when men are incorporated into reproductive programs, typically women-oriented in the past, health providers are trained to attend the new male clientele.

Although the interventions described increased the demand for contraceptive services, future research into the topic should search for alternatives to solving, in a more effective manner, some of the challenges posed by this study: how to approach sexual and reproductive rights in ways that men find acceptable and yet preserve women's autonomy; how to keep female methods from displacing male methods; and how to increase use of male methods. 
Title:

Institution:

Researcher:

Effects of Training Supervision on The Quality of Care at Health Facilities

\section{CARE Bolivia}

\section{Wilma Llanos S.}

In 1995, CARE Bolivia started the project "Our Bodies, Our Health" to improve sexual and reproductive health services in rural areas of the Departments of Tarija, Potosí, and Santa Cruz. To that end, in coordination with SEDES-Tarija, Plan Internacional and UNFPA$\mathrm{PAHO} / \mathrm{WHO}$, the project prepared a training supervision instrument.

This supervision instrument was designed to guide facilitators to conduct their technical visits. The purpose is to have facilitators and health personnel jointly use this instrument and improve the quality of care by continuous training of health providers. The instrument revolves around five topics: administrative management; theoretical concepts in reproductive health; counseling and supervision; information, education and communication; and understanding and use of the client's perspective.

The objective of this study was to evaluate the effects of the training supervision strategy on quality of care, in two districts of the Department of Tarija and two districts of the Department of Santa Cruz. The facilitators, including the CARE teams of the cities of Montero and Tarija, were trained at each health district -Villamontes, Warnes, Padcaya, and Norte.

This study followed an experimental design and used pre and post-intervention evaluations. Ten health facilities in each district participated in the study. Twenty facilities were assigned to the experimental group and 20 to the control group.

The most important findings of the study were:

- Applying the training supervision strategy to sexual and reproductive health services contributes to improving quality of care at health facilities (see Figure 1).

- Use of the training supervision strategy improves communication among district authorities, SEDES, and health providers.

- District teams are encouraged by this type of supervision, as it creates an environment of trust, respect, and mutual support for training.

- Client perceptions regarding the quality of treatment, skills, and information given by the provider is low in the four districts, even after four supervisions.

- The supervision team's decision power to assume or delegate responsibilities at health facilities can be the key to the success of the process. In addition, the lack of continuity of supervision and coordination problems can negatively affect the process. 
Figure 1. Quality of care in four districts

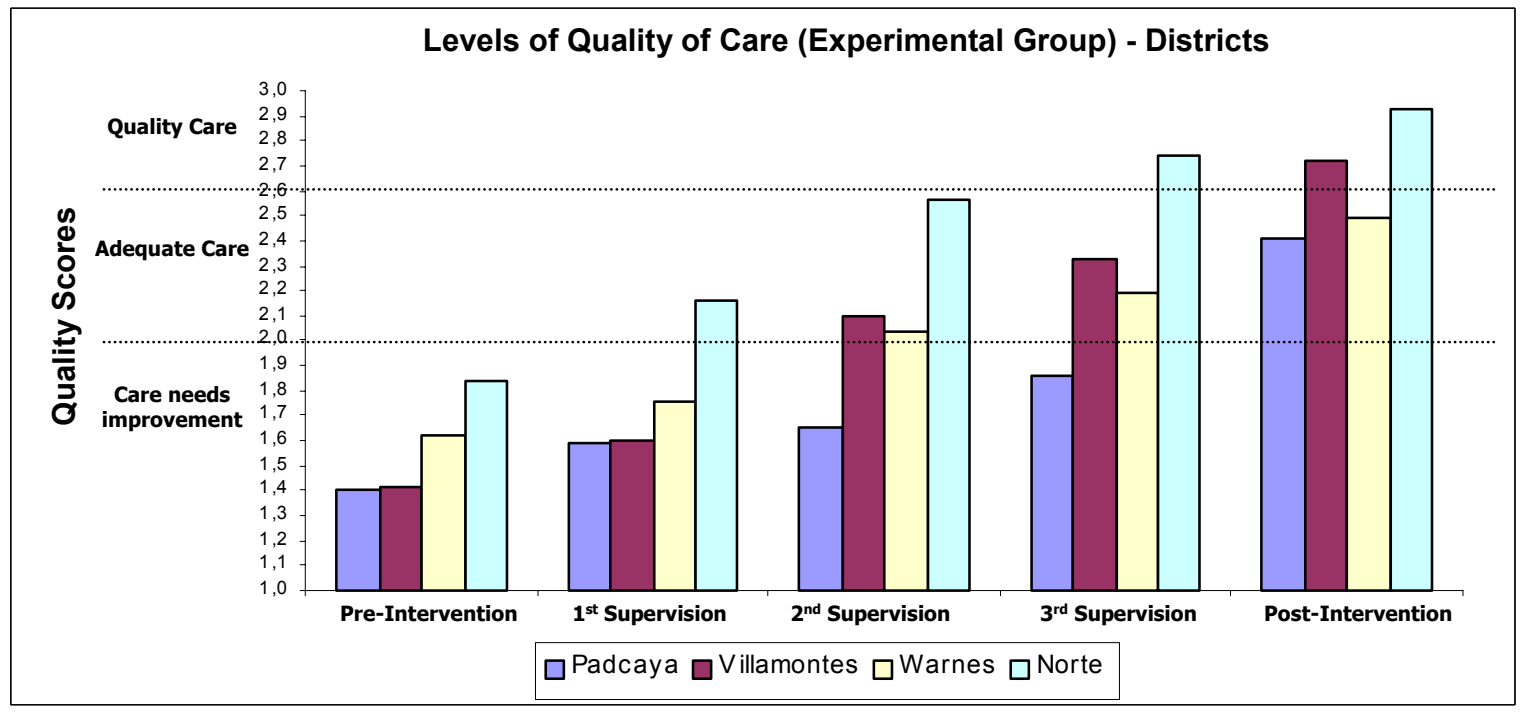

Based on the results of this study, continuous application of the training supervision strategy at all Ministry of Health facilities and completing the preparation and implementation of an integrated training supervision instrument appears both useful and necessary. 
Title:

Institution:

Researchers:

\title{
Need Detection In Sexual And Reproductive Health Programs
}

\author{
Cáritas Boliviana, Department of Health
}

\author{
Dr. Óscar Fernando Robles Saldaña \\ Lucio Lantaron Núñez
}

Cáritas Boliviana, a social assistance institution, member of the Episcopal Conference, conducted an operations research study within the context of its project "Improved Sexual and Reproductive Health Practices among Women of Reproductive Age. "The objective of this study was to identify the needs of the population in sexual and reproductive health and use this information to improve the activities and competencies of health promoters. From the institutional perspective, this information is essential to optimize interventions and enhance service coverage.

As part of its routine service delivery activities, a mobile health team conducts visits twice a month to different communities. During the visits, the health team - consisting of a physician and two nurses- provides child health, and sexual and reproductive health services. In addition to working with this mobile team and first care facilities, Caritas carries out activities with voluntary promoters from the communities.

During their visits to the communities, health providers noted that the mobile team recorded only the spontaneous demand for services. To improve the team's performance, health providers suggested that promoters identify each family's specific needs before the visits. Thus, data obtained by promoters would be passed along to the health team to enhance service, improve performance, and increase the project's coverage. To implement the strategy, similar experiences by other organizations were reviewed and a female consultant specialized in the topic was hired. This consultant developed a series of forms that allow segmenting the population according to their sexual and reproductive health needs. This job aids were then used by community promoters and volunteers.

The study was conducted in 22 communities of the Chuma Municipality, Province of Muñecas, situated in the Department of La Paz, Bolivia, from March to December 2000. The study site was located in a remote mountainous region; its population is scattered over small communities constituted by 60 families on average.

The study followed a quasi-experimental design, with time series in the experimental group and a control group. Eleven communities were assigned to the experimental group and eleven to the control group. Health promoters of the communities assigned to the experimental group were trained in the use of the segmentation forms and received a consultation guide to offer basic information during the interview. Data were collected in three-month periods -two quarters prior and two after the intervention.

The results suggest that the use of the segmentation forms can be a significant aid to enhance service coverage. Family planning counseling is the only case that due to the number of consultations allows statistical inferences; the number of consultations recorded 
for the experimental group was significantly higher than that for the control group. As for the other cases, even when the number of reported consultations was very small, there was always a favorable tendency among communities where the segmentation forms were used.

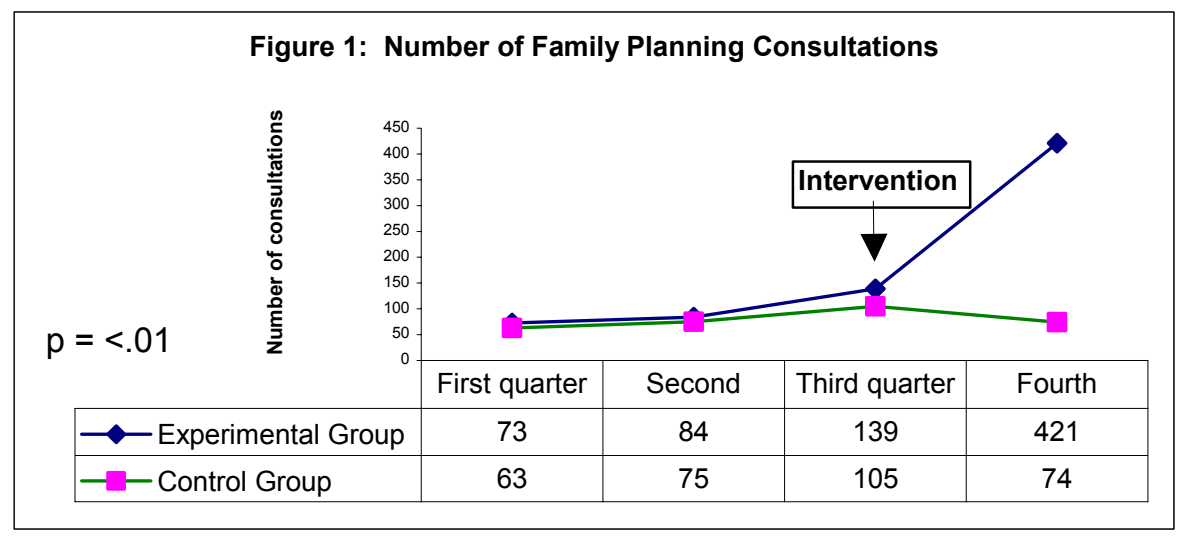

This study reinforces the assumption that there is unmet demand for family planning methods.

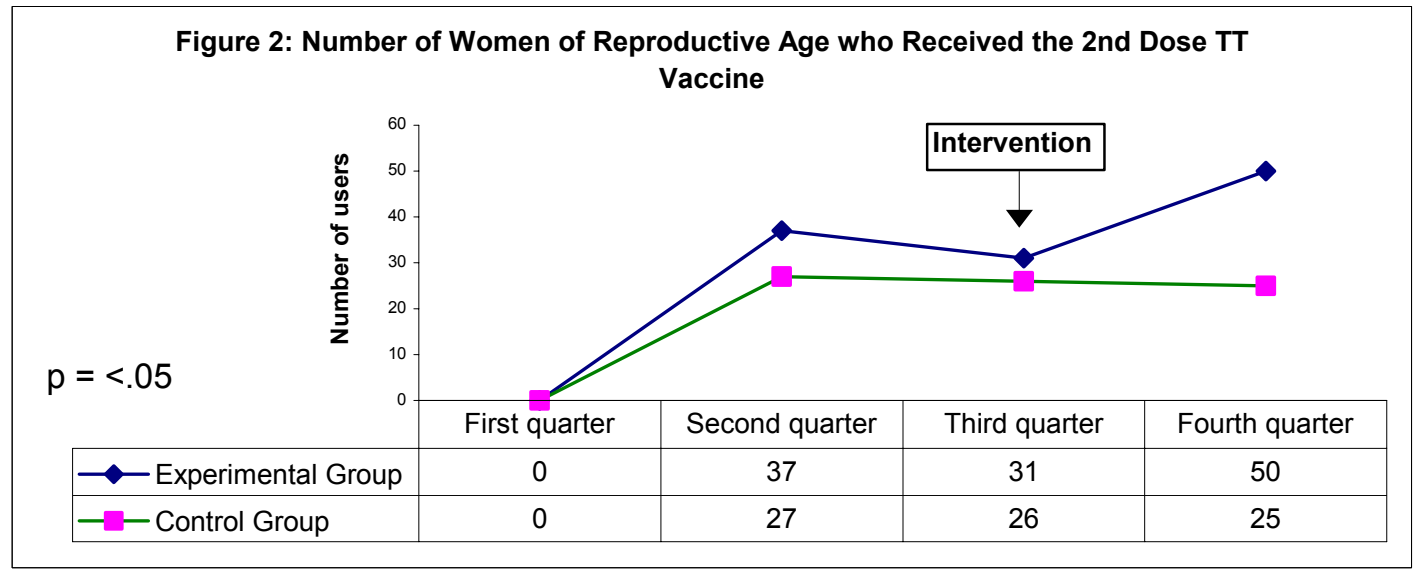

Results showed that promoters used the forms less frequently than expected, which undoubtedly affected the outcome.

One of the most surprising findings was that demand for information on family planning was highest among the male population. There is the possibility that topics related to pregnancy and labor are still considered "intimate". Therefore, obtaining data in that regard was difficult using village promoters.

In conclusion, the researchers recommend utilizing the instruments tested in this study to increase coverage of sexual and reproductive health programs. 
Title:

\section{Institution:}

Researcher:

\section{Home Visits as a Strategy to Reduce Unmet Demand}

$$
\text { Andean Rural Health Council - Montero (CSRA - M) }
$$

The Andean Rural Health Council (in Spanish, CSRA) is a non-governmental organization that works with a household visit strategy entitled Impact-Oriented Census-Based Methodology. This methodology includes a variable number of visits to each household, depending on the sort of programs the institution conducts and the number and characteristics of family members.

The objective of this study was to test the impact of household visits on the reduction of unmet need among women who do not use contraceptive methods, and on the increase of knowledge of the fertile cycle among users of the rhythm method. During the visit, the health agent would try to determine if the woman wanted to get pregnant in the following two years and if she was using a contraceptive method. If she did not want to get pregnant and was not using a method, the promoter would talk about the methods she could use and refer her to health services. If the woman said she was using the rhythm method, the promoter would try to determine if she was using it correctly; if she was not, he/she would provide information on its correct use. The researchers expected that the intervention would increase contraceptive use prevalence in Villa Cochabamba (Montero, Santa Cruz) by supporting free choice among women who do not want a pregnancy in the coming years and promoting the correct use of the rhythm method among women who said they were using the method.

Two designs were used: an experimental design with a control group to evaluate the impact of the intervention on the reduction of unmet demand among the 96 women who during the first visit said that they did not want to have more children in the following two years and were not using a contraceptive method; and a non-experimental design to evaluate the impact on quality of use of the rhythm method among the 50 women who during the first visit said that they were using it. In both cases, pre and post-intervention observations were conducted. 


\section{Figure 1. Evolution of the group with unmet demand after the intervention Changes in Unmet Demand - Experimental Group}

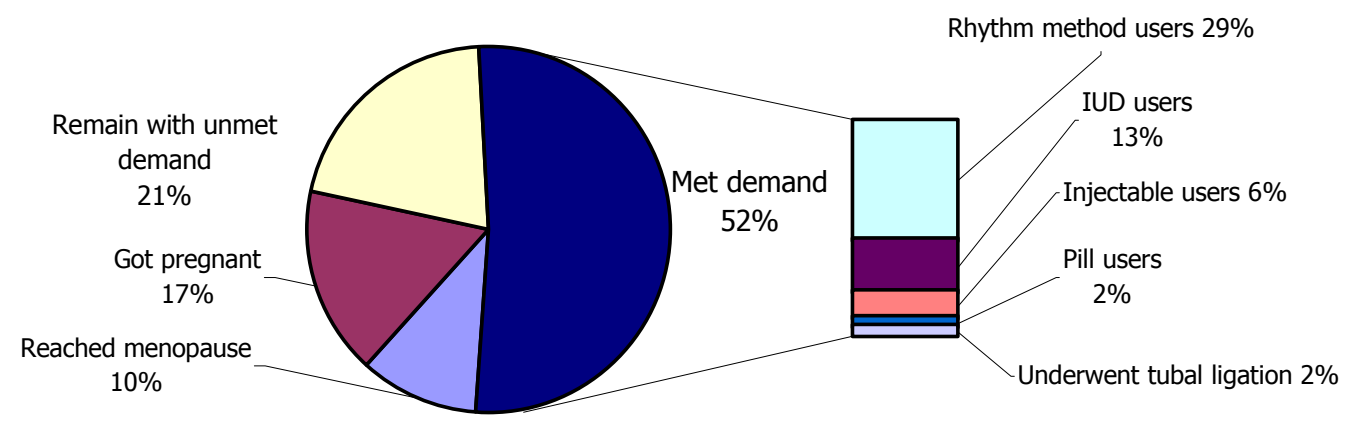

Use of the technique of systematized home visits resulted in a considerable reduction in unmet demand, with the rhythm method being the preferred choice of women who decided to use family planning (see Figure 1).

The levels of knowledge on the fertility cycle among female users of the rhythm method were slightly higher than baseline knowledge. However, this increase cannot be regarded as a success indicator. The need for better techniques to teach the use of the rhythm method seems evident.

This research showed that including an average of four systematized household visits with sexual and reproductive health contents has a positive impact, as it provides adequate alternatives that meet the demand for contraceptive methods among women who do not want a pregnancy in the near future.

A recommendation derived from this study is to incorporate the strategy of systematized home visits into sexual and reproductive health programs and community programs on education in health. 
Title:

Institution:

Researchers:

Effective Strategies to Improve Quality of Care

ESPERANZA Bolivia: San Lucas Municipality - Department of Chuquisaca

\author{
Ruth Crespo Ruth \\ Juan Antonio Plaza Zamorano \\ Míriam Vargas Vargas
}

ESPERANZA Bolivia, a non-governmental organization and member of the PROCOSI Network, conducted the operations research study "Effective Strategies to Improve Quality of Care in Reproductive Health Services".

This study followed a quasi-experimental design with an experimental (San Lucas) and a control municipality (Culpina). These sites were chosen based on similarities such as accessibility, geographical characteristics, population, location of health facilities, and availability of human resources, and then randomly assigned to one of the study groups.

Research activities started in July 2000 with a pre-intervention evaluation that utilized six instruments: a questionnaire to evaluate the health providers' level of knowledge; guides to conduct direct observation of prenatal and labor care and Pap smear sampling; a checklist to evaluate a service's organization; and a questionnaire to interview users after consultations.

At a later stage, a training program for all health workers in the experimental municipality was developed. This program included sensitization and motivation topics with a focus on the user to provide quality care, improve processes, leadership, self-esteem, include a gender perspective, interculturality, norms and procedures for prenatal and labor care, and Pap smear sampling. At each workshop, an action plan was prepared and then implemented at experimental services.

To monitor the interventions, a committee for the improvement of quality, constituted by Municipal authorities, community members, and health district and hospital personnel, was organized.

The results of the study show that health providers' knowledge regarding reproductive health care norms and skills to provide prenatal control improved. Observation of labor care procedures and Pap smear sampling revealed improvements similar to those of prenatal control, as shown in the following figure: 
Figure 1. Procedures Correctly Applied by Service Providers during Prenatal Control, by Group and Period

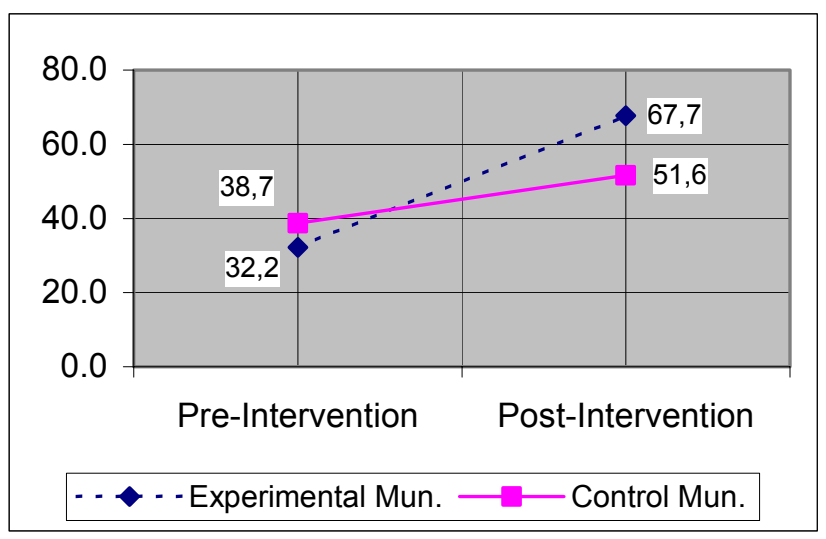

$\mathrm{P}=0.027$

The percentage of users satisfied with the care provided increased from $68 \%$ at the preintervention stage to $95 \%$ post-intervention, a marginally statistically significant result.

Figure 2. Users Satisfied with Care Provided at Health Services in the Experimental and Control Municipalities

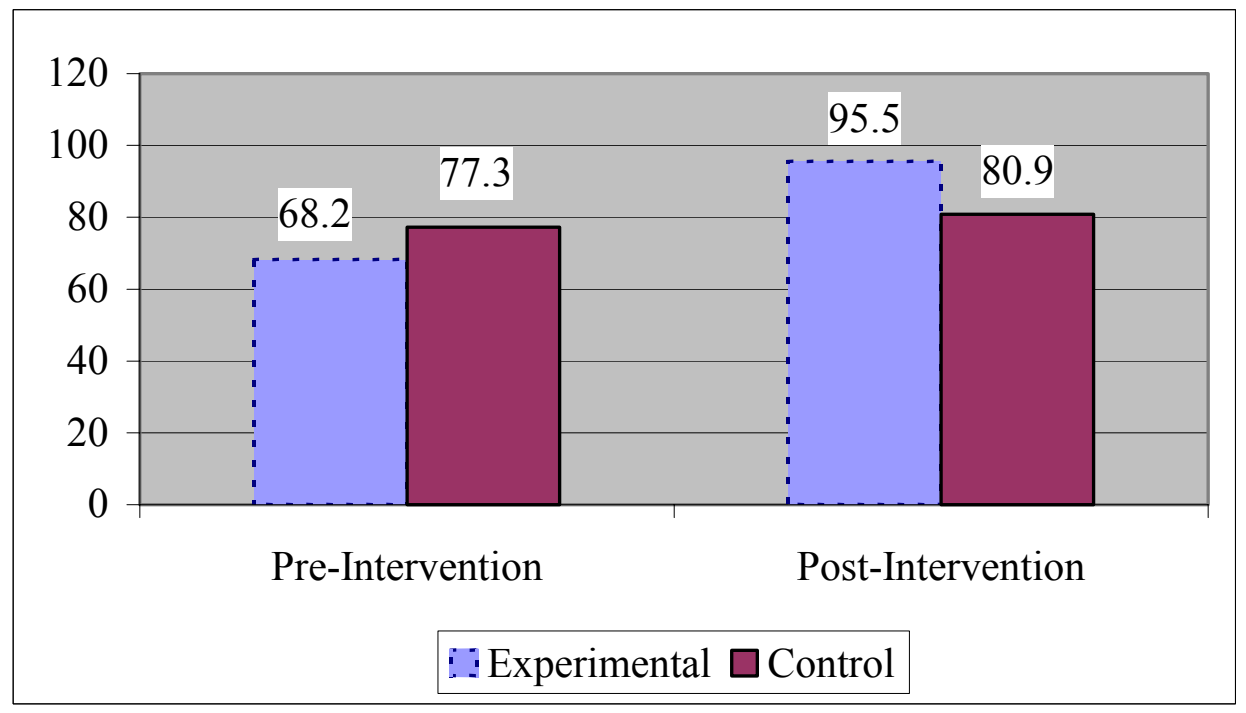

$$
\mathrm{P}=0.062
$$

This operations research study also had an impact on the coverage of the program on women's care being implemented by ESPERANZA Bolivia. Coverage of prenatal control, labor care, and Pap smear sampling increased significantly, especially among women who attend prenatal control before the fifth month of pregnancy. 
Although most of the study variables were favorably modified by the interventions, improvement in many cases was not statistically significant. Factors such as the reduced number of observations may have influenced the results of the analysis.

Based on the study results, we may conclude that training health providers to improve quality of care should include preparation of action plans that contemplate activities, tasks, personnel in charge, and deadlines. Action plans should be part of a permanent follow-up and evaluation program, if favorable results are to be obtained.

Organizing committees for the follow-up of quality improvement is essential. The creation of such committees allows communities to share the objectives of the health sector and providers.

Based on this experience, ESPERANZA Bolivia is replicating the methodology implemented at control municipality facilities. Afterwards, the same methodology will be implemented in the other areas of influence of the program. Additionally, an algorithm for norms and procedures is being prepared to help health providers improve service delivery efficiency. 
Title:

Institution:

\section{Researchers: $\quad$ Lieselotte V. Barragán Bauer José V. Barragán Bauer}

From April 2000 to September 2001, the San Gabriel Foundation conducted an operations research study to "facilitate the population's access to health services through an innovative prepayment system". Simultaneously, this organization sought to explore the efficacy of interventions regarding hospital financial sustainability.

This non-profit, private organization and a leading service provider in health, has 30 years' experience and operates in the III Sanitary District, east zone of La Paz, Bolivia. It works with a service network that includes: a) a secondary-care facility with 120 beds, support units for diagnosis and treatment, and basic medicine, pediatrics, gynecology and obstetrics, and surgery specialties, and pathology as subspecialty; and b) an outpatient care system in the III Sanitary District that consists of two medical centers with capacity for basic pathology services (Kupini and Valle Hermoso), and two polyclinics (Pampahasi and Villa Armonía), with pediatrics and gynecology and obstetrics specialties. The service network of the San Gabriel Foundation provides an average of 62,000 consultations a year and 11000 secondary-care consultations, of which 6,973 are provided by the gynecology and obstetrics service.

The Foundation noted a growing trend in the number of labor and prenatal control consultations provided by the service network. This trend resulted from the recent boost the Ministry of Health has given to the Basic Health Insurance, which includes provision of care to pregnant woman as part of its package of free benefits. Additionally, due to the country's economic recession and the fact that users were not able to pay for services, the number of contingent credits increased. This represents a problem, as credits are granted under disadvantageous conditions for the Foundation and are rarely reimbursed.

This operations research study tested the hypothesis that strengthening the prepayment and credit systems for users of health services provided by the San Gabriel Foundation, specifically for high-risk pregnancies, will enhance access to secondary-care services, hence increasing demand and sustainability.

The intervention sought to improve a prepayment system known as the "Stork Plan", whereby users pay installments at their prenatal control visits and in time complete full payment of labor expenses before delivery. Another modality used was to establish credit contracts and prepayment plans for users requiring hospitalization. These innovations to the payment systems were accompanied by an IEC (flyers, posters, and radio spots) campaign to inform about these new ways of accessing hospital services.

Among the most relevant findings are the following: 


\section{Figure 1. Scheduled credits}

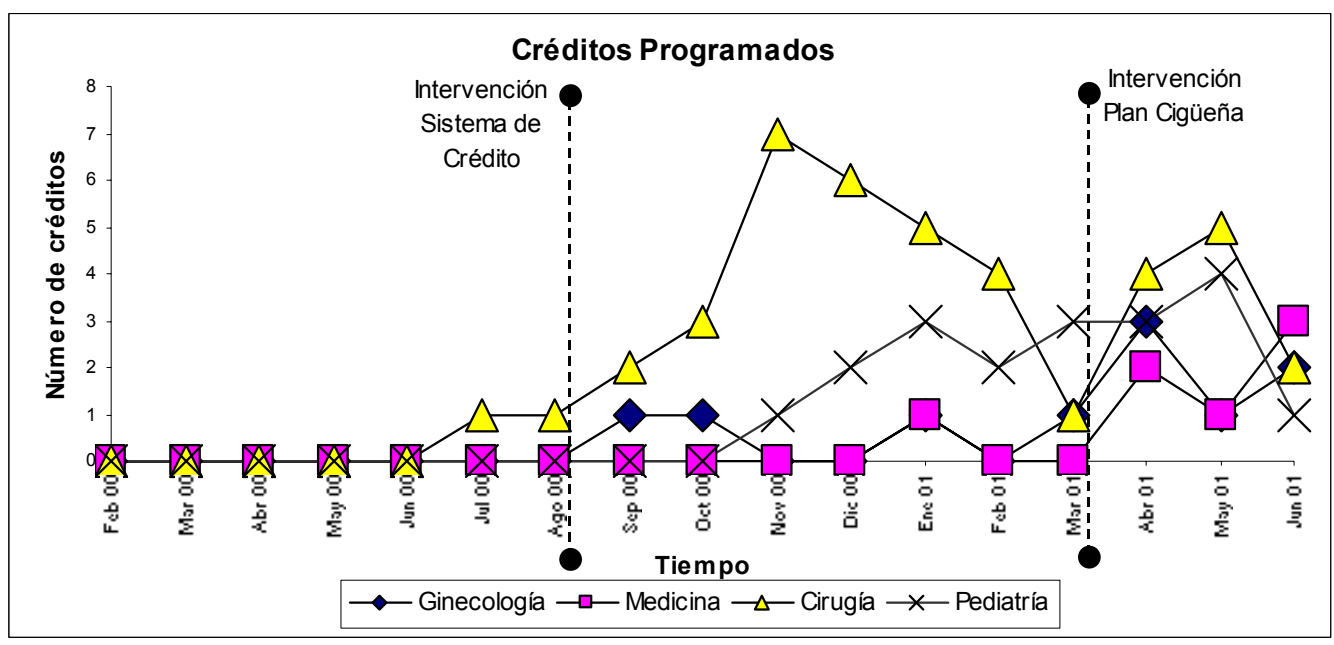

For gynecological services, scheduled credits and prepayments under the "Stork Plan" showed a rising trend. However, they decreased in May with the inauguration of the Mother Child Hospital of the National Health Fund, which offers free services within the framework of the Basic Health Insurance (see Figure 1).

Figure 2. Contingent credits

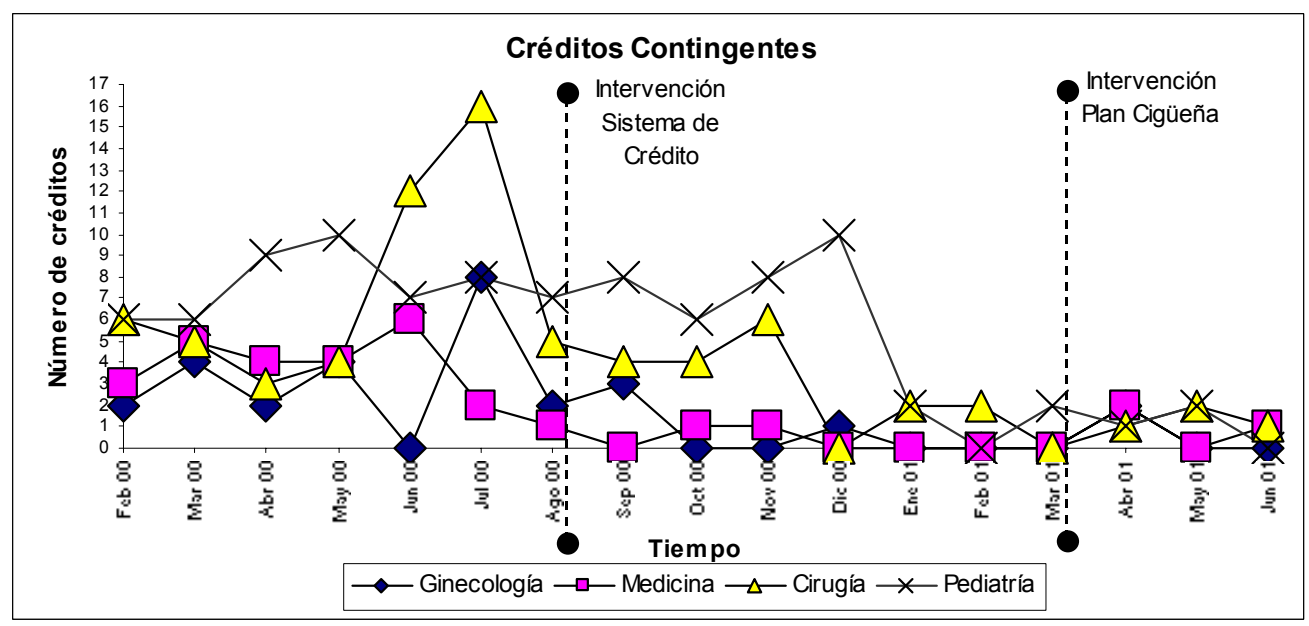

The introduction of scheduled credits before provision of hospital services resulted in a reduction in contingent credits, which demonstrates greater willingness by users to negotiate the cost of the service before receiving it (see Figure 2).

The credit system did not affect outpatient services significantly, as opposed to services that require hospitalization, such as surgery, pediatrics, medicine, and gynecology, where the number of users grew. Based on this result, increased economic accessibility can be 
inferred. However, credit and prepayment plans did not improve significantly the hospital's financial income or sustainability.

Based on the findings of this research, our recommendations are the following:

- The credit system offered by the institution is a feasible option and constitutes an instrument that improves the population's access to some health services.

- At present, as part of its strategic plan, the San Gabriel Foundation is developing innovative initiatives for the integrated care of pathologies not covered by the Basic Insurance, particularly those that demand higher levels of care. The credit system is one of these initiatives.

- Due to promotion difficulties and the opening of the Mother Child Hospital of the National Health Fund, the prepayment system oriented to sexual and reproductive health care was not adequately evaluated. Therefore, further follow-up for two additional quarters is recommended.

- Strengthening promotion of the credit system through the media is important. Increasing the number of users of credit programs could contribute towards larger hospital income or at least, fewer losses originated by contingent credits. 
Title:

\section{Institution: $\quad$ PRO MUJER}

\section{Researcher: $\quad$ Patricia Claure}

PRO MUJER is a private, non-profit, social development organization that serves four cities in Bolivia: Cochabamba, Sucre, Tarija, and El Alto. At present, PRO MUJER serves more than 10,000 clients in the city of El Alto. This population consists mostly of marginalized women with limited access to financial, educational, and health services. In view of this situation, PRO MUJER provides services such as credit and savings, business development, human development, and basic health, including sexual and reproductive health (SRH) counseling and consultations.

Basic health services were implemented three years ago, as part of the package of benefits granted to credit service users. Supervision of these services revealed that different teams used different criteria and procedures to provide SRH counseling, due partly to a lack of a training and supervision system for the standardization of contents and procedures.

To solve this problem, this organization decided to give formal and on-the-job training to 29 PRO MUJER healthcare providers assigned to the experimental group, emphasizing quality of SRH counseling and respect for women's rights.

A result of this training was that providers' knowledge and practices improved significantly. For example, the proportion that was able to explain the meaning of SHR increased 21 percent points, and an observation of counseling sessions showed that at the end of the project providers complied virtually with all the necessary criteria to establish good communication. Additionally, the percentage of providers that explained the characteristics of at least three contraceptive methods during counseling sessions increased from $44 \%$ (pre-intervention) to $100 \%$ (post-intervention). In both the control and the experimental groups, significant improvements in the percentage of women who said they had received enough information and cordial treatment were noted.

In spite of statistically significant changes, providers' knowledge and attitudes remained relatively low after the intervention. For instance, after training, only $31 \%$ thought that women were the ones to decide what contraceptive method to use. In like manner, the percentage of providers that were able to describe the five steps of the counseling model increased from $3.4 \%$ (baseline) to a relatively low $27.5 \%$ (post-intervention).

As for the process, during the first training supervision visit, observations revealed that providers frequently did not put into practice what they had learned during formal training. However, as a result of the suggestions made by the supervisor, during the second visit observers noted significant improvements in the experimental group, a trend that persisted in later visits. 
This operations research project showed that training alone does not suffice; it is necessary to include a training supervision component for changes to take place and quality of service to improve. Training supervision changes the perceived "censoring" quality of traditional supervision by adding value and transforming it into an accepted element that provides support and feedback about the performance of health providers. 


\section{APPENDIX 2}

\section{SUMMARIES OF ADOLESCENTS PROJECTS}


Title:

Institution:

Researchers:
Diagnosis on Affectivity, Sexuality, and Sexual and Reproductive Health Among Teachers in The City of La Paz

Educational Multi-Service Center (CEMSE)

An organization that is dependent on the Compañía de Jesús (Jesuits) in Bolivia, the Educational Multi-Service Center (in Spanish, CEMSE) has worked in education and health for 15 years. At present, CEMSE serves 45 public schools that serve around 20,000 students, more than 1,000 teachers, and roughly 7,000 families.

CEMSE is known for developing innovative educational strategies that served as references for the Education Reform and have been applied nationwide for years. Over the last five years, this organization has been developing curricular proposals for public secondary education -a level that has not derived benefits from the Education Reform- in areas such as mathematics, social sciences, natural sciences and ecology, communication and language; and in cross cutting (transversal) training such as education for health and education in affectivity and sexuality.

Of particular importance and difficultly in education is the application of cross-cultural training in affectivity, sexuality, and sexual and reproductive health. Such training is relevant to the integrated formation of the child and often does not occur within the family or at school in a fashion that meets the needs of youth. Indeed, school teachers do not assume this responsibility for a variety of reasons, such as a lack of the necessary elements to educate on sexuality, absence of appropriate methodologies, a feeling of shame and the belief that these matters are to be dealt with exclusively within the family or by specialists.

This educational vacuum at the family level has made it necessary for schools to satisfy education and preventive needs linked to sexuality and sexual activity. In fact, this is contemplated by the Education Reform Law that has been in effect in the country as a result of implementing Education in Health and Sexuality.

This study followed a descriptive, exploratory design. It identified the perceptions of teachers regarding this theme to develop basic guidelines to design training in sexuality and incorporate it into the regular curricula for teacher formation.

This study was conducted with the participation of teachers, students and parents from five primary schools and five secondary schools, which were randomly selected among the 23 education facilities with which CEMSE has agreements.

Three methodologies were utilized: surveys conducted with 254 teachers from the 10 schools selected; focus groups with teachers (4 groups, 44 participants), students (4 groups, 
40 participants), and parents (2 groups, 30 participants), and classroom observations (9 observations, 7 at secondary schools, and 2 at primary schools).

The most relevant results of this study are:

- More than $60 \%$ of the teachers do not have clear concepts of affectivity, sexuality, and sexual and reproductive health.

- Teachers have communication problems and difficulties to express feelings to their students. This has a negative impact on the education process, as evidenced by observations at classrooms, where students were almost always silent recipients of educational activities.

- Teachers argued that they did not feel sufficiently trained to answer students' questions about these topics.

- Teachers demand greater knowledge on these subjects. They think that courses and workshops could help them improve their professional skills.

- Adolescents complain that adults -teachers and parents- do not discuss sexuality and sexual health with them. Their need for communication and education on these topics is fulfilled by friends. They demand greater communication and education from both their parents and teachers.

On the whole, this study provides information to design a curriculum on affectivity, sexuality, and sexual and reproductive health for teachers. However, further research should be conducted, particularly in regards to strategies for the implementation of crosscultural training for students.

The results of this research were published and presented at a seminar attended by teachers from fiscal education units and education and health authorities. The findings of this study are being used as input for the preparation of a curriculum for training in affectivity and sexuality, within the perspective of the Education Reform. 
Title:

Institutions:

Researchers:

\title{
A Gender Perspective in Adolescents' Training in Sexual and Reproductive Health
}

\author{
Save the Children Canada \\ Center for Women's Studies and Work (CETM)
}

\section{Sonia Díaz Gómez \\ Sonia Pardo Burgoa}

Save the Children Canada (SCC) is a non-governmental organization that seeks to improve the quality of life of rural populations, an endeavor based on the premise that "children are protagonists of development". SCC works through a network of associate NGOs; the Center for Women's Studies and Work (in Spanish, CETM) is a member of this network and is in charge of conducting operations research.

CETM's mission is to improve children and women's living conditions, while fostering integrated health. For eight years, this organization has collaborated with several programs in the Sacaba Municipality in Bolivia. As for activities with adolescents, CETM conducted the "Integrated Child Development Program" with children and adolescents aged 8 to 19. Through this experience, the worrisome high prevalence of unwanted pregnancies among adolescents was corroborated. This problem has been neglected by other institutions.

The objective of this study was to show how efficacious training in sexual and reproductive health with a gender perspective is in increasing knowledge and promoting responsible attitudes among adolescents from education facilities.

This operations research effort was implemented with the participation of a segment of population from the Sacaba Municipality, in the first municipal section of the Province of Chapare, 15 kilometers from the Department of Cochabamba. The study population consisted of 195 male and female adolescents, the totality of third and fourth graders from four schools. The study followed a quasi-experimental design with a non-equivalent pre and post-evaluation control group. Adolescents were randomly assigned to the control and the experimental groups.

Students were trained using didactic-pedagogical materials with a focus on gender and through active participatory workshops. Health personnel from the Hospital México in Sacaba conducted the training. 
Figure 1. Knowledge on contraceptive methods

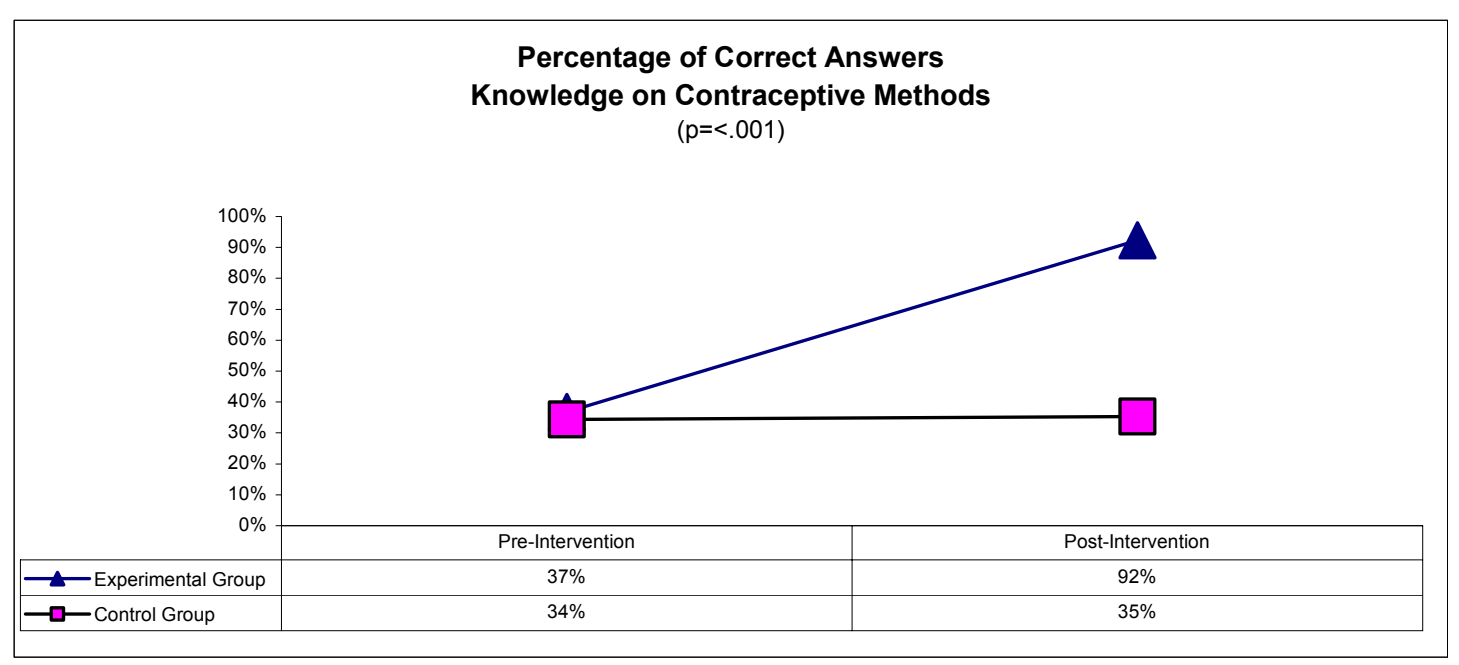

Figure 2. Attitude towards sexuality, gender, and human rights

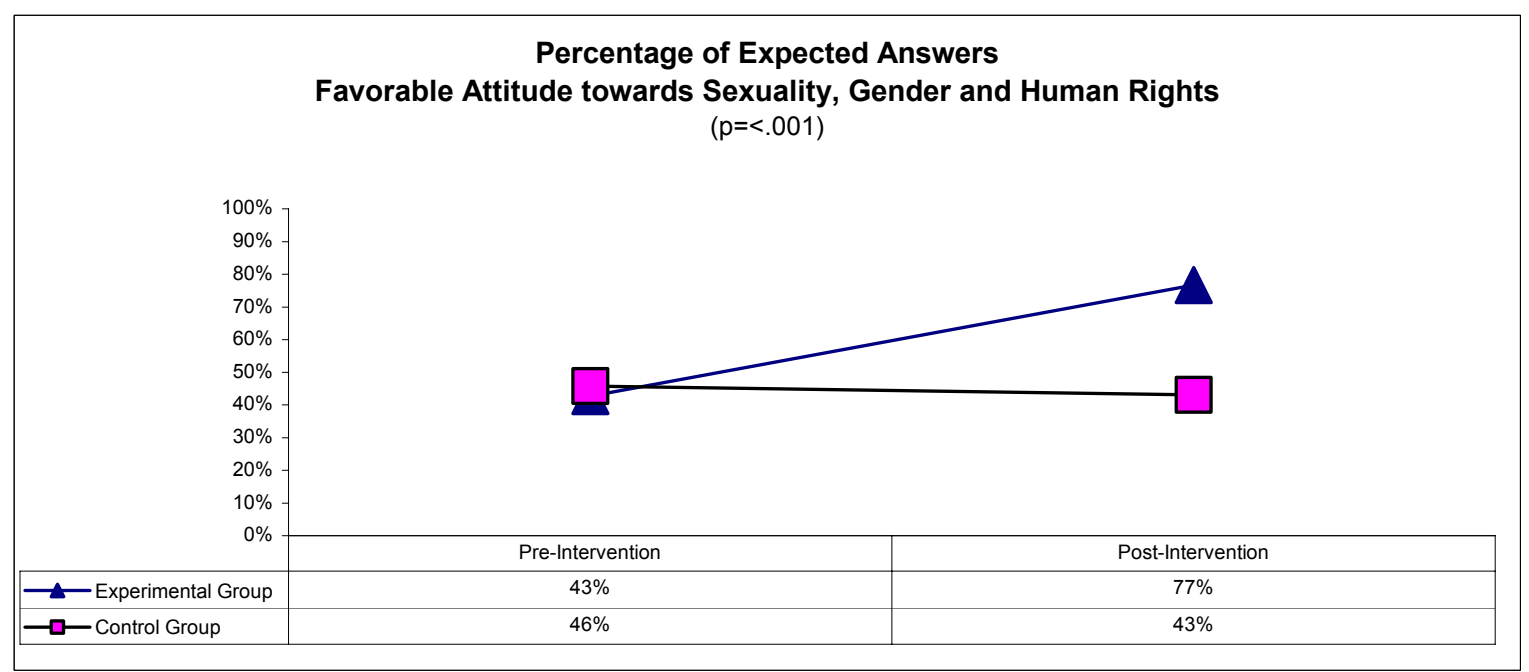

The results of this research showed that the students of the experimental group improved considerably their knowledge on sexuality, family planning methods (see Figure 1), and sexually transmitted infections. Their sensitivity and favorable attitudes towards gender equity and human rights also improved (see Figure 2).

Socio-affective and family communication attitudes did not develop significantly, because those changes depend on a series of factors that involve parental attitudes towards children, and cannot be modified through training.

The results show that through educational-informative workshops, knowledge and favorable attitudes of adolescents towards sexual and reproductive health can be enhanced. This can lead to an integrated practice of their sexual and reproductive health, where women and men share responsibility. 
Based on the positive results of this research, we recommend that other sexual and reproductive health programs use the methodology and educational materials employed during the intervention. 
Title:

Institution:

Researcher:
Adolescents and Sexuality: What Do They Need to Know and Who is Supposed to Teach Them?

\section{NUR University}

\section{Roberto Baker}

NUR University is a non-profit education organization, affiliated with PROCOSI, that has worked in health since 1988. The organization's activities include development of postgraduate courses in public health, hospital management, and rural medicine and nursing. Among ongoing efforts are extension projects in women's leadership for health, integrated care for childhood diseases, youth leadership, and sexual education for adolescents.

A strategy that NUR wishes to implement, within the scope of its Youth Leadership Project, is peer education in sexual and reproductive health. Since evidence of the effectiveness of this strategy was inconclusive, NUR decided to carry out a diagnostic study to determine to a greater extent the expectations of adolescents regarding peer education, and based on the results of such diagnosis prepare a training curriculum aimed at youth leaders.

The study was conducted between April and December 2000, in the city of Santa Cruz. For diagnosis purposes, self-administered tests among a population of college students and youth leaders of the project were utilized, and focus groups and in-depth interviews were conducted.

The results of this participatory study will allow adolescents with the NUR Youth Leadership Project to define their roles and responsibilities as peer educators; close information gaps among the adolescent population; improve the training contents and strategies of the project's sexual education component; and propose changes to the university's education program, as indicated by the analysis. However, effective support for teachers and authorities involved in the planning, design, and decision-making processes are essential. 
Figure 1. Knowledge about contraceptive methods

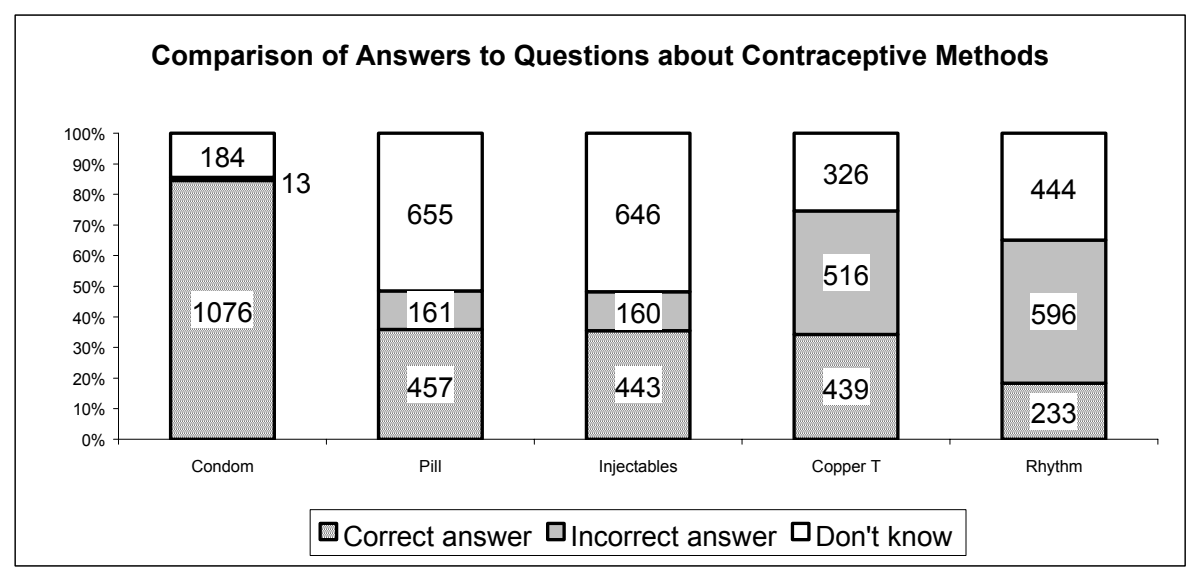

The diagnosis revealed a lack of knowledge on contraceptive methods, in general, and characteristics of a woman's fertile cycle, in particular. The most widely known method is the condom. Less than half the study population has basic knowledge on the pill, injectables, and the Copper T (see Figure 1). However, a large percentage of adolescents know the transmission mechanisms of STIs and AIDS (not shown).

Figure 2. Whom adolescents turn to

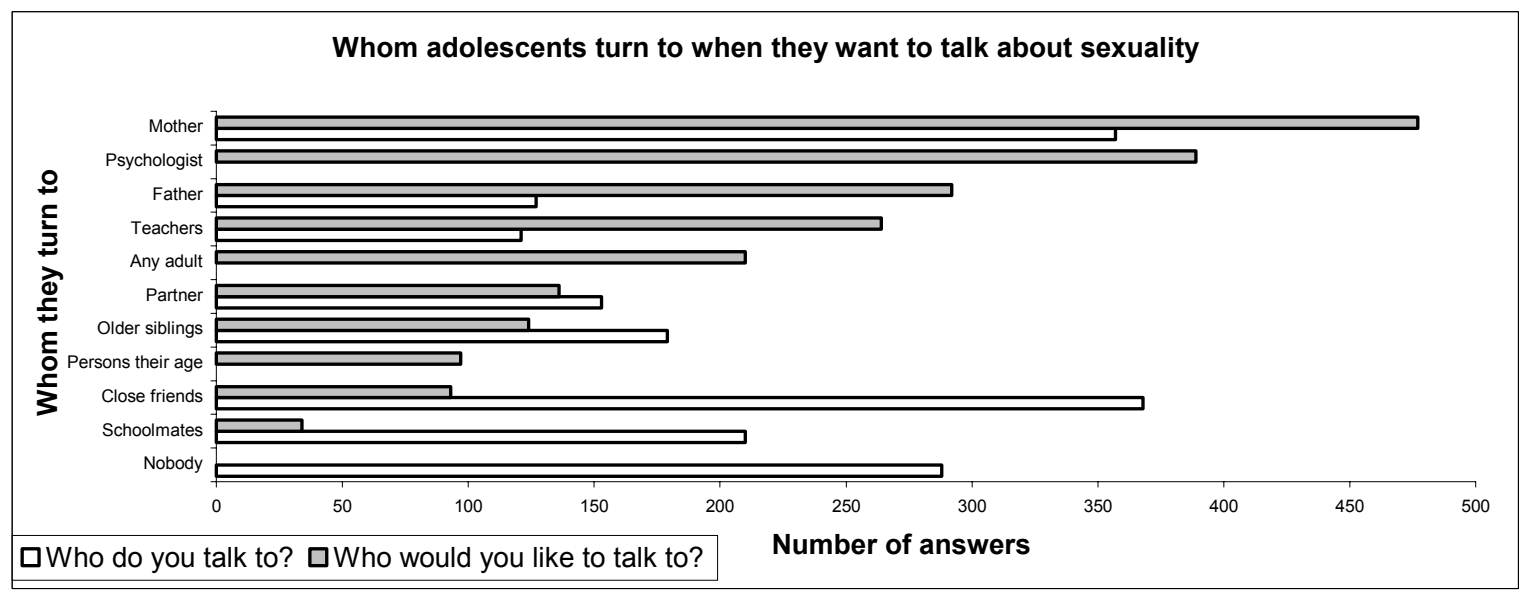

Although many adolescents talk about sexuality with their friends and schoolmates, they would rather talk about this matter with adults than with people their age, because they get erroneous or incomplete information. Unfortunately, adults do not create an environment of trust and openness to establish the level of communication adolescents require (see Figure 2).

To implement a system to transmit information through peer educators, it is necessary to create an environment of trust and credibility among adolescents and educators their age. The latter must be very well trained in all sexual and reproductive health-related topics and 
possess charm. Surely, the process of acceptance by these adolescents will be slow, but if quality of information is ensured, this system could be very effective in the mid-term.

With the collaboration of the faculty of the NUR University, the path forward is to design a curriculum in sexual and reproductive health topics aimed at adolescents, in accordance with the findings of this study. 
Title:

Institution:

Researchers:

\title{
Interactive Training in Gender Equity for Adolescents
}

\author{
Radio Education - Integrated Services Program \\ (PER - SI)
}

\author{
Betty Barrón Achá \\ Jaime Reyes Velásquez \\ Virginia Roncal Revollo
}

Work with adolescents on gender equity is a growing need. Contemplated by the Education Reform in Bolivia, this program regards gender perspective together with health, sexuality, environment, and democracy as a cross cutting theme of its curriculum.

The Radio Education - Integrated Services Program (in Spanish, PER - SI) is very experienced at developing interactive methodologies, which are used for the dissemination of formal and non-formal education programs on the radio. Based on such experience, this operations research designed and tested an educational methodology that included the use of audiocassettes. Training in gender equity was provided to seventh and eighth-graders of fiscal primary schools in the city of Oruro, Bolivia.

For the purposes of this study, interactive methodology was defined as training in gender equity for adolescents, conducted by a facilitator who used audiocassettes and a study guide.

Research activities were conducted in 2001, with the participation of 258 students, 43 teachers, and 40 parents. Self-administered tests for the students and focus groups with the adults were utilized. The educational process included training for the teachers, so that they could implement the audio programs in the classroom and use support materials (teacher's guide and student's book).

At the end of the study, through questionnaires and orally, students said they approved and were motivated by the use of the interactive methodology with audiocassettes. Additionally, the student's books, course song, and program messages met with their approval. Regarding gender equity, 14 out of the 19 questions of the self-administered questionnaire produced favorable results for the research: both men and women improved their knowledge. 
Figure 1: Attitudes of Students towards Gender Roles

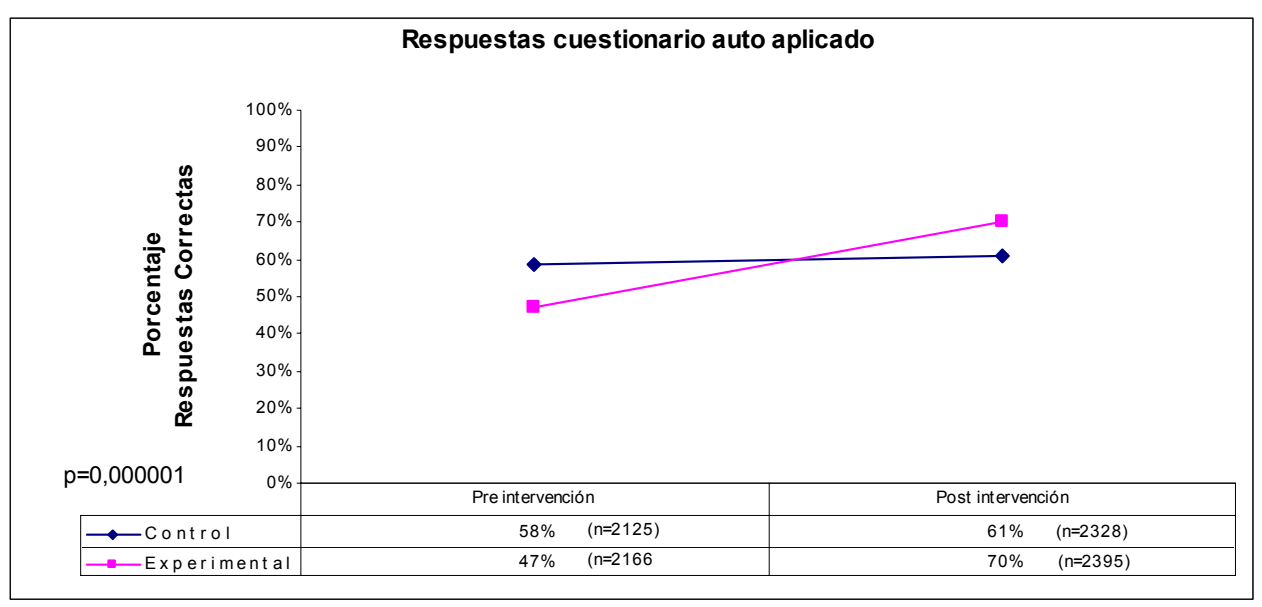

\section{Total number of correct answers - attitudes towards gender}

Students' self-esteem, defined as a positive self-appraisal and an appreciation of one's abilities/skills, remained unchanged. However, agreement with the statement "the more we value ourselves, the more we will be able to value others" did increase among both women and men.

The following table shows that knowledge on sex and equity increased considerably. An analysis by gender revealed that such increase was similar for men and women. Selfesteem and gender also increased among women, but decreased among men, who apparently are confused about these concepts.

Table 1: Percentage of students who described concepts correctly

\begin{tabular}{|c|c|c|c|c|}
\hline \multirow[b]{2}{*}{ CONCEPT } & \multicolumn{2}{|c|}{ CONTROL GROUP } & \multicolumn{2}{|c|}{ EXPERIMENTAL GROUP } \\
\hline & $\begin{array}{c}\text { Pre- } \\
\text { Intervention } \\
(\%) \\
\end{array}$ & $\begin{array}{c}\text { Post- } \\
\text { Intervention } \\
(\%) \\
\end{array}$ & $\begin{array}{c}\text { Pre- } \\
\text { Intervention } \\
(\%) \\
\end{array}$ & $\begin{array}{c}\text { Post- } \\
\text { Intervention } \\
(\%) \\
\end{array}$ \\
\hline Sex & 16 & 19 & 27 & 64 \\
\hline Equity & 9 & 6 & 22 & 50 \\
\hline Self-esteem & 18 & 24 & 30 & 64 \\
\hline Gender & 0 & 0 & 0 & 12 \\
\hline
\end{tabular}

Education and development institutions could benefit from the use of this interactive methodology when working with adolescents, as it proved to be efficacious in reaching a larger number of individuals in less time, as compared to the conventional workshop methodology. 
Title:

Institution:

Authors:

Pharmacies: The Main Source of Orientation and Contraceptive Methods for adolescents

\author{
Save the Children Federation
}

\title{
Elizabeth Arteaga \\ Ivonne La Fuente
}

For the past four years, Save the Children/Bolivia (SC/B) has been carrying out a sexuality education program called "Making Decisions" in the city of Oruro, Bolivia. The program addresses approximately 4,000 adolescents between 10 and 19 years old who come from public schools and an alternative system (evening schools). Teachers, mothers and fathers, and health providers also participate in the program. Its goal is to provide adolescents with accurate, up-to-date information on sexual and reproductive health, including information related to the option of freely exercising and enjoying their sexuality. The program also facilitates access to high-quality services in Oruro, both in terms of orientation and supply of contraceptive methods, through two local health centers of the Health and Social Security Ministry.

A KAP study on adolescent sexuality that was carried out in 1999 as part of the baseline for a new project, revealed that private pharmacies in the city of Oruro were the main source of information and contraceptive methods for adolescents. Since personnel in these establishments was not part of the target population for training in quality of care, SC/B decided to carry out this operations research study aiming to test the following hypothesis: "Sensitizing and training pharmacists in topics related to adolescents' sexual and reproductive health, as well as improving promotion systems, counseling, and contraceptive method supply to adolescents, will increase adolescent's satisfaction, levels of trust, and the number of adolescent clients of the pharmacies."

With a quasi-experimental design, results obtained at four experimental group pharmacies were compared with four control group pharmacies. Interventions involved both providers (pharmacy personnel) and clients (adolescents).

Provider interventions consisted of a series of training workshops for pharmacists on contraceptive technology, ongoing quality improvement processes, sensitization in adolescent issues, and sexual and reproductive rights. EngenderHealth and Population Services International (PSI) participated in the development of these interventions and provided technical assistance. On the other side, clients -adolescents- received training in sexuality, contraception, and sexual and reproductive rights as part of SC/B's regular program.

The intervention also included a series of activities to bring pharmacy professionals and adolescents together. Meetings to negotiate expectations were held, and an IEC campaign with various printed materials was developed. 
Information for evaluating aspects of the quality of services was gathered through a registration form for services provided by pharmacies, and through simulated clients. Results showed an increase of 130 percent in the demand for orientation services in the experimental group, compared to 37 percent in the control group.

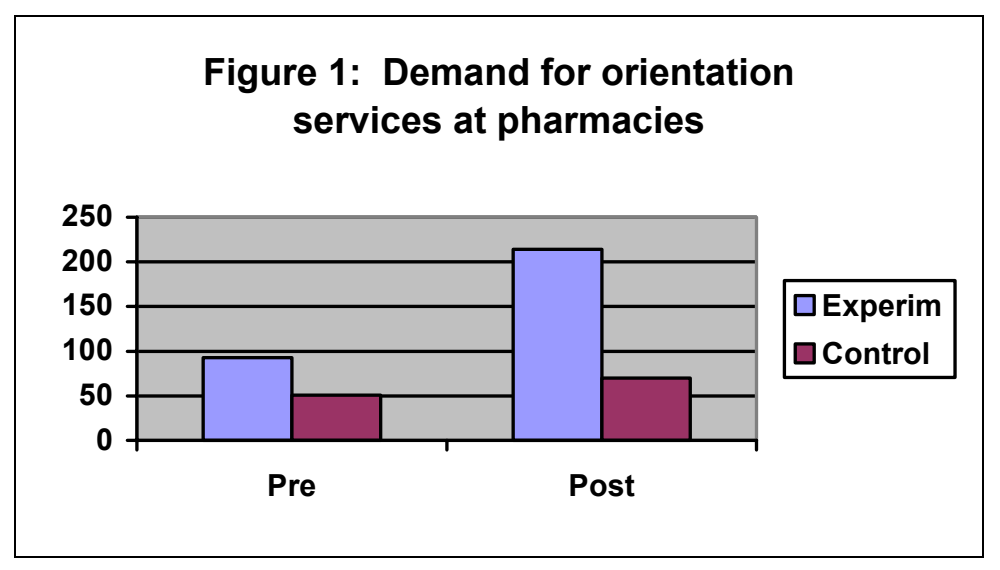

The number of contraceptives sold to sexually active adolescents also increased significantly: for example, sales of condoms increased by almost five times after the intervention. Sales of other methods such as vaginal tablets and injections (DepoProvera) also increased. The demand for methods was similar for both sexes.

Changes were observed after the intervention, using the simulated client technique. The most notable changes were found in the sensitivity developed by pharmacists to help adolescents not feel embarrassed, and also in the improved quality of information provided on contraceptive methods. Nevertheless, it was also observed that the information provided to adolescents is still incomplete and fails to include all the contraceptive methods. These deficiencies can be attributed to a number of factors: the limited time that pharmacists can offer when they are simultaneously attending to various clients; the fact that the complete range of methods is not available; and, likely, commercial interest in specifically promoting certain contraceptives.

In the experimental pharmacies, the simulated clients (both female and male) said they felt comfortable most of the time when interacting with the pharmacists: "He was very nice... and politely handed me the method..." "She didn't ask me anything, and treated me very calmly... she didn't react or make any comment." "She calmly sold me the method I asked for." "The pharmacist has a lot of patience for adolescents and she's well-prepared." On a few occasions, they mentioned that the pharmacists' "seriousness" was a factor that made them uncomfortable: "He was very serious." "She was really cold, and could have explained things to me a little more naturally."

In contrast, in the control pharmacies, some simulated clients said they were uncomfortable with the attention received: "She looked at me surprised." "I got a shocked look." "At first, he greeted me, but when I left, there was no response. " "She was very abrupt in giving me an explanation... she should explain things calmly." 
The study demonstrated that encouraging clients to become actively involved is a fundamental strategy for building genuine processes of participation. The 260 adolescent leaders who participated in the intervention phase and who know their rights as clients visited the pharmacies for approximately 45 minutes (divided in groups of five). During this period of time, they could talk with pharmacists and create opportunities for the pharmacists to listen to their clients, which increased the motivation of these providers to carry out the work of providing high-quality orientation in sexual and reproductive health for adolescents. In addition, the adolescent leaders were able to promote the message accompanying the IEC campaign of "Pharmacies are your allies" among their peers.

This study, which tested interventions on a small scale (four pharmacies), demonstrated the validity of the strategies used to increase the access of adolescents to pharmacies, and to improve the quality of the information and supply of contraceptives to adolescents. These strategies consisted of: a) training for technicians and professionals at pharmacies on topics relevant to high-quality services in supplying contraceptives and providing orientation to adolescents; b) information and education for clients (adolescents) on relevant issues; c) encouraging involvement of adolescent leaders; and d) an information campaign through small communication media.

The "Making Decisions" program did not originally include working with pharmacy personnel as one of its strategies. The findings from this study reveal that it is strategically necessary to include pharmacies in what we have referred to as the "Network of highquality services for adolescents' integral health" in the city of Oruro. As a result of this study, $\mathrm{SC} / \mathrm{B}$ is including 14 pharmacies in its new intervention strategies. 
Title:

IEC Strategy Improves Knowledge and Attitudes Towards Sexual and Reproductive Health Among Adolescents in Caranaví.

Institution: $\quad$ SERVIR

Researchers: $\quad$ Patricia Ballivián

Ronny Benito

Freddy Chambi

Javier Palacios

SERVIR is a non-profit, private organization that provides opportunities to improve the quality of life of a target population. Since 1991, SERVIR has carried out health and education activities in Caranaví (rural area of the Department of La Paz) through mobile interdisciplinary teams that reach remote, highly dispersed communities that rarely receive assistance.

Due to the high number of pregnancies among students and a lack of sexual and reproductive health information and services, principals, teachers, and parents from public secondary schools in Caranaví requested SERVIR educational activities for adolescents, which had not been implemented by the health and education systems.

SERVIR conducted an operations research study that showed that an IEC strategy in sexual and reproductive health could improve knowledge and attitudes among eighth-grade and first and second-year secondary school adolescents, at a public school in Caranaví. The study followed a design that used a single group and pre and post-intervention evaluations. The intervention consisted of a series of training workshops for the students. To evaluate the effects of the intervention, a self-administered questionnaire on knowledge, attitudes, and practices of the study group was used.

Additionally, the researchers sought to improve the quality of sexual and reproductive healthcare for adolescents provided at private pharmacies and health centers by training their personnel. To evaluate the impact of these interventions, observations using the "simulated client" technique were conducted. Additionally, focus groups with parents and teachers were held.

The results of the study showed the following:

- Adolescents' knowledge on the anatomy and physiology of reproduction, and on contraception improved $25 \%$. 
Table 1: Knowledge on Contraceptive Methods

\begin{tabular}{|c|c|c|}
\hline \multirow{2}{*}{ Method } & \multicolumn{2}{|c|}{ Number and percentage of correct answers } \\
\hline & Pre & Post \\
\hline Pill & $51(11 \%)$ & $172(45 \%)$ \\
\hline IUD & $25(6 \%)$ & $185 \quad(48 \%)$ \\
\hline Depo-Provera & $43(9 \%)$ & $126(33 \%)$ \\
\hline Condom & $149(33 \%)$ & $291 \quad(77 \%)$ \\
\hline Tubal Ligation / Vasectomy & $295(67 \%)$ & $229 \quad(60 \%)$ \\
\hline
\end{tabular}

- Adolescents increased their level of knowledge on the various mechanisms of contracting STIs (21\%) and HIV/AIDS (28\%). However, no changes in misconceptions about contagion occurred.

- There is still unmet need for information on topics related to menstruation and partner relations.

- Adolescents said they wanted to have their first child at 20-25 years of age and limit their family size to two children.

- After the educational intervention, demand for counseling in sexual and reproductive health increased 20 percent, and demand for medical services in sexual and reproductive health increased 119 percent.

Figure 1: Adolescents Who Requested Medical Sexual and Reproductive Health Services a the SERVIR Policlinic

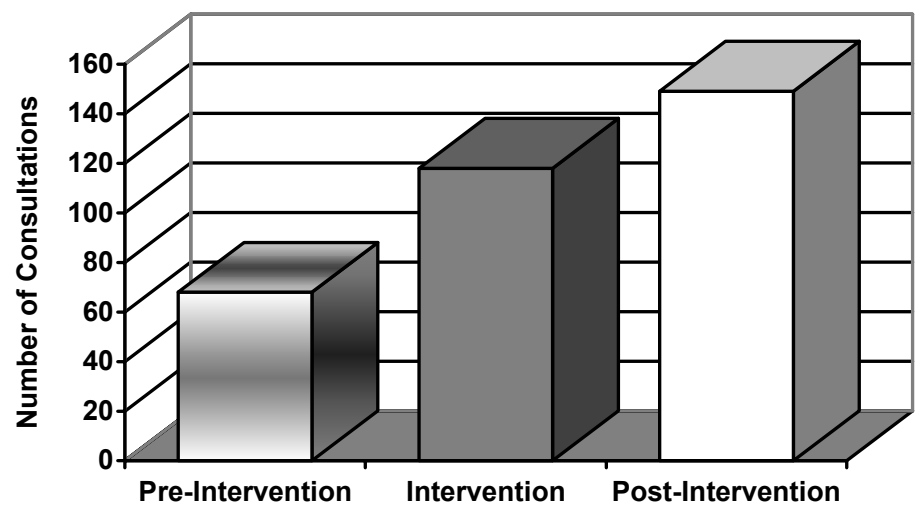

With the "simulated client" technique, the quality of care provided to adolescents by health workers improved. 
The results of this operations research study led to a better understanding of adolescents and the language that should be used during service delivery. The recommendations derived from this study include the following: more training for service providers and pharmacy attendants is needed to better fulfill the information and counseling needs of adolescents; adolescent-oriented education modules should place emphasis not only on the mechanisms of contracting STIs and HVI/AIDS, but also on misconceptions about forms of contagion. 